\title{
Solar Energy Prediction for Malaysia Using Artificial Neural Networks
}

\author{
Tamer Khatib, ${ }^{1}$ Azah Mohamed, ${ }^{1}$ K. Sopian, ${ }^{2}$ and M. Mahmoud ${ }^{3}$ \\ ${ }^{1}$ Department of Electrical, Electronic \& System Engineering, Faculty of Engineering \& Built Environment, \\ National University of Malaysia, 43600 Bangi, Selangor, Malaysia \\ ${ }^{2}$ Solar Energy Research Institute, University Kebangsaan Malaysia, 43600 Bangi, Selangor, Malaysia \\ ${ }^{3}$ Department of Electrical Engineering, Engineering Faculty, An-Najah National University, Nablus 97300, Palestine
}

Correspondence should be addressed to Tamer Khatib, tamer_khat@hotmail.com

Received 6 January 2012; Accepted 6 April 2012

Academic Editor: Jincai Zhao

Copyright (c) 2012 Tamer Khatib et al. This is an open access article distributed under the Creative Commons Attribution License, which permits unrestricted use, distribution, and reproduction in any medium, provided the original work is properly cited.

\begin{abstract}
This paper presents a solar energy prediction method using artificial neural networks (ANNs). An ANN predicts a clearness index that is used to calculate global and diffuse solar irradiations. The ANN model is based on the feed forward multilayer perception model with four inputs and one output. The inputs are latitude, longitude, day number, and sunshine ratio; the output is the clearness index. Data from 28 weather stations were used in this research, and 23 stations were used to train the network, while 5 stations were used to test the network. In addition, the measured solar irradiations from the sites were used to derive an equation to calculate the diffused solar irradiation, a function of the global solar irradiation and the clearness index. The proposed equation has reduced the mean absolute percentage error (MAPE) in estimating the diffused solar irradiation compared with the conventional equation. Based on the results, the average MAPE, mean bias error and root mean square error for the predicted global solar irradiation are $5.92 \%, 1.46 \%$, and $7.96 \%$. The MAPE in estimating the diffused solar irradiation is $9.8 \%$. A comparison with previous work was done, and the proposed approach was found to be more efficient and accurate than previous methods.
\end{abstract}

\section{Introduction}

Solar energy is the portion of the sun's energy available at the earth's surface for useful applications, such as raising the temperature of water or exciting electrons in a photovoltaic cell, in addition to supplying energy to natural processes like photosynthesis. This energy is free, clean, and abundant in most places throughout the year. Its effective harnessing and use are of importance to the world, especially at a time of high fossil fuel costs and the degradation of the atmosphere by the use of these fossil fuels. Solar radiation data provide information on how much of the sun's energy strikes a surface at a location on the earth during a particular time period. These data are needed for effective research into solar energy utilization. Due to the cost of and difficulty in solar radiation measurements, these data are not readily available; therefore, alternative ways of generating these data are needed. A comprehensive solar radiation database is an integral part of an energy efficiency policy $[1,2]$. In
Malaysia, there are cities/regions that do not have measured solar radiation data; therefore, a predication tool should be developed to estimate the potential of solar energy based on location coordinates.

In recent years, ANNs have been used in solar radiation modeling work for locations with different latitudes and climates, such as Saudi Arabia, Oman, Spain, Turkey, China, Egypt, Cyprus, Greece, India, Algeria, and the UK [3-34]. Little work regarding solar energy prediction has been done for Malaysia. The only significant prediction methods have been proposed in [35, 36] in 1982 and 1992. The authors in [35] have only proposed solar radiation data for three locations without any prediction algorithms, while the authors in [36] have proposed a prediction algorithm for monthly solar radiation based on the least square linear regression analysis using eight data locations. Consequently, an ANN model for solar energy prediction should be developed to provide a comprehensive database for the solar energy potential in Malaysia. Moreover, the proposed ANN model will be more 


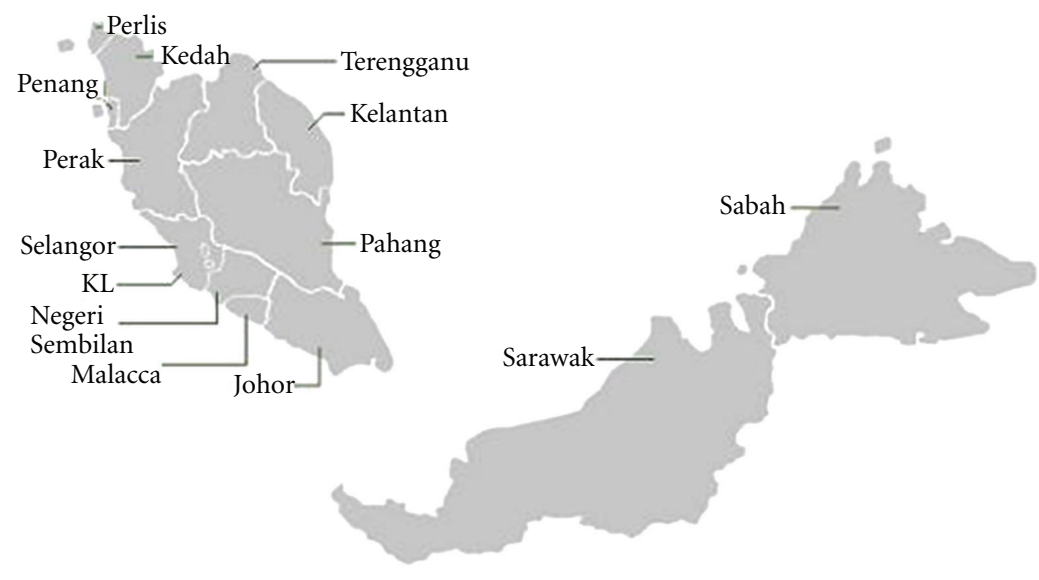

FIgURE 1: Malaysia political map.

accurate than the proposed methods in $[35,36]$, and it will provide hourly, daily, and monthly solar radiation predictions for many different locations in Malaysia because the location coordinates are provided.

The main objective of this paper is divided into two subobjectives: develop a feed forward ANN model to predict the clearness index $\left(K_{T}\right)$ based on the number of sunshine hours, day number, and location coordinates and calculate the global $\left(E_{T}\right)$ and diffused $\left(E_{D}\right)$ solar irradiations based on the developed formulas for Malaysia. This work has been based on long-term data for solar irradiations (1984-2004) taken from the 28 sites in Malaysia. These data were provided by the Solar Energy Research Institute (SERI) of Universiti Kebangsaan Malaysia (UKM).

\section{Malaysia's Climate Profile}

Figure 1 shows a political map of Malaysia. Malaysia is an Asian country located in the Far East and consists of eleven states with two separated main lands.

Malaysia has a hot, humid tropical climate with two monsoon seasons: one between October and February and the other from April to October; the latter is characterized by thunderstorms. Temperatures and humidity are high year round, but the mountains are slightly cooler. Table 1 shows the climate profile for 10 sites in Malaysia. In this table, three metrological variables are used: ambient temperature, rain precipitation, and sunshine hours.

From Table 1, it is clear that Malaysia has a cloudy sky and stable climate during the year; therefore, a low average solar irradiation with a low deviation is expected for all months. However, Long-term (1984-2004) metrological data containing the global irradiation, diffused irradiation, clearness index, sunshine hours, humidity, ambient temperature, rainfall, and air pressure have been taken from these sites to develop and test the proposed ANN model.

\section{Solar Energy Prediction Model}

Solar radiation is classified in two main parts: the extraterrestrial solar irradiation $\left(E_{\text {extra }}\right)$ and the global solar irradiation
$\left(E_{T}\right)$. The variable $E_{\text {extra }}$ stands for the total solar energy above the atmosphere, while $E_{T}$ is the total solar energy under the atmosphere. The value for $E_{\text {extra }}$ is given by $[1,2]$

$$
E_{\text {extra }}=\left\{I_{o}\left[1+.034 \cos \left(\frac{2 \pi N}{365}\right)\right]\right\} * \text { Day length, }
$$

where $I_{o}$ is the solar constant, $1,367 \mathrm{~W} / \mathrm{m}^{2}$, and $N$ is the number of the day.

The day length is calculated by $[1,2]$

$$
\text { Day length }=\frac{2}{15} \cos ^{-1}(-\tan L \tan \delta),
$$

where $L$ is the latitude and $\delta$ is the angle of declination, given by

$$
\delta=23.45 \sin \left[\frac{360(284+N)}{365}\right] .
$$

The global solar irradiation $\left(E_{T}\right)$ on a tilted surface consists of three parts:

$$
E_{T}=E_{B}+E_{D}+E_{R}
$$

where $E_{B}, E_{D}$, and $E_{R}$ are beam (direct), diffused, and reflected solar irradiation, respectively. On a horizontal surface, $E_{R}$ is equal to zero; therefore, $E_{T}$ on a horizontal surface is given by

$$
E_{T}=E_{B}+E_{D}
$$

The global $\left(E_{T}\right)$ can be calculated using $E_{\text {extra }}$ as follows:

$$
\frac{E_{T}}{E_{\text {extra }}}=K_{T},
$$

where $K_{T}$ is the sky clearness index. After finding $E_{T}, E_{D}$ can be calculated using

$$
\frac{E_{D}}{E_{T}}=f\left(K_{T}\right) .
$$

To find an appropriate function that describes (7) accurately, the right and left sides of (7) should be drawn in an $x-y$ plot, 
TABLE 1: Malaysia climate profile.

\begin{tabular}{|c|c|c|c|c|c|c|c|c|c|c|c|c|c|}
\hline \multirow{2}{*}{ City } & \multirow{2}{*}{ Climate } & \multicolumn{12}{|c|}{ Max./min. temperature, rainfall, and sunshine duration } \\
\hline & & 1 & 2 & 3 & 4 & 5 & 6 & 7 & 8 & 9 & 10 & 11 & 12 \\
\hline \multirow{4}{*}{ Kuala Lumpur } & Max. & $32^{\circ} \mathrm{C}$ & 33 & 33 & 33 & 33 & 32 & 32 & 32 & 32 & 32 & 31 & 31 \\
\hline & Min. & $22^{\circ} \mathrm{C}$ & 22 & 23 & 23 & 23 & 23 & 23 & 23 & 23 & 23 & 23 & 23 \\
\hline & Rain & $159 \mathrm{~mm}$ & 154 & 223 & 276 & 182 & 120 & 120 & 133 & 173 & 258 & 263 & 223 \\
\hline & Sun & $6 \mathrm{hr}$ & 7 & 7 & 7 & 7 & 6 & 6 & 6 & 5 & 5 & 5 & 5 \\
\hline \multirow{4}{*}{ Malacca } & Max. & $32^{\circ} \mathrm{C}$ & 33 & 33 & 32 & 32 & 31 & 31 & 31 & 31 & 31 & 31 & 31 \\
\hline & Min. & $22^{\circ} \mathrm{C}$ & 23 & 23 & 23 & 23 & 23 & 23 & 23 & 23 & 23 & 23 & 23 \\
\hline & Rain & $90 \mathrm{~mm}$ & 104 & 147 & 184 & 166 & 172 & 181 & 178 & 206 & 216 & 237 & 142 \\
\hline & Sun & $7 \mathrm{hr}$ & 7 & 7 & 7 & 7 & 6 & 7 & 6 & 6 & 6 & 5 & 5 \\
\hline \multirow{4}{*}{ Penang } & Max. & $32^{\circ} \mathrm{C}$ & 32 & 32 & 32 & 31 & 31 & 31 & 31 & 31 & 31 & 31 & 31 \\
\hline & Min. & $23^{\circ} \mathrm{C}$ & 23 & 24 & 24 & 24 & 24 & 23 & 23 & 23 & 23 & 23 & 23 \\
\hline & Rain & $70 \mathrm{~mm}$ & 93 & 141 & 214 & 240 & 170 & 208 & 235 & 341 & 380 & 246 & 107 \\
\hline & Sun & $8 \mathrm{hr}$ & 8 & 8 & 7 & 7 & 7 & 7 & 6 & 5 & 5 & 6 & 7 \\
\hline \multirow{4}{*}{ Kota Bahru } & Max. & $29^{\circ} \mathrm{C}$ & 30 & 31 & 32 & 33 & 32 & 32 & 32 & 32 & 31 & 29 & 29 \\
\hline & Min. & $22^{\circ} \mathrm{C}$ & 23 & 23 & 24 & 24 & 24 & 23 & 23 & 23 & 23 & 23 & 23 \\
\hline & Rain & $163 \mathrm{~mm}$ & 60 & 99 & 81 & 114 & 132 & 157 & 168 & 195 & 286 & 651 & 603 \\
\hline & Sun & $7 \mathrm{hr}$ & 8 & 9 & 9 & 8 & 7 & 7 & 7 & 7 & 6 & 5 & 5 \\
\hline \multirow{4}{*}{ Kuala Terengganu } & Max. & $28^{\circ} \mathrm{C}$ & 29 & 30 & 31 & 32 & 32 & 31 & 31 & 31 & 30 & 29 & 26 \\
\hline & Min. & $22^{\circ} \mathrm{C}$ & 23 & 23 & 23 & 24 & 23 & 23 & 23 & 23 & 23 & 23 & 23 \\
\hline & Rain & $174 \mathrm{~mm}$ & 99 & 109 & 101 & 103 & 108 & 110 & 141 & 184 & 266 & 643 & 559 \\
\hline & Sun & $7 \mathrm{hr}$ & 7 & 8 & 8 & 8 & 7 & 7 & 7 & 6 & 6 & 5 & 4 \\
\hline \multirow{4}{*}{ Kuantan } & Max. & $29^{\circ} \mathrm{C}$ & 31 & 32 & 33 & 33 & 33 & 32 & 32 & 32 & 32 & 30 & 29 \\
\hline & Min. & $21^{\circ} \mathrm{C}$ & 22 & 22 & 23 & 23 & 23 & 23 & 23 & 23 & 23 & 23 & 22 \\
\hline & Rain & $311 \mathrm{~mm}$ & 165 & 166 & 169 & 192 & 164 & 162 & 179 & 233 & 273 & 318 & 591 \\
\hline & Sun & $5 \mathrm{hr}$ & 6 & 7 & 7 & 7 & 6 & 6 & 6 & 6 & 5 & 4 & 3 \\
\hline \multirow{4}{*}{ Johor Bahru } & Max. & $31^{\circ} \mathrm{C}$ & 32 & 32 & 32 & 32 & 32 & 31 & 31 & 31 & 31 & 31 & 30 \\
\hline & Min. & $21^{\circ} \mathrm{C}$ & 22 & 23 & 23 & 23 & 23 & 22 & 22 & 22 & 22 & 22 & 22 \\
\hline & Rain & $146 \mathrm{~mm}$ & 155 & 182 & 223 & 228 & 151 & 170 & 163 & 200 & 199 & 255 & 258 \\
\hline & Sun & $6 \mathrm{hr}$ & 6 & 6 & 6 & 6 & 5 & 5 & 5 & 4 & 5 & 4 & 5 \\
\hline \multirow{4}{*}{ Cameron Highlands } & Max. & $21^{\circ} \mathrm{C}$ & 22 & 23 & 23 & 23 & 23 & 22 & 22 & 22 & 22 & 22 & 21 \\
\hline & Min. & $14^{\circ} \mathrm{C}$ & 14 & 14 & 15 & 15 & 15 & 14 & 15 & 15 & 15 & 15 & 15 \\
\hline & Rain & $120 \mathrm{~mm}$ & 111 & 198 & 277 & 273 & 137 & 165 & 172 & 241 & 334 & 305 & 202 \\
\hline & Sun & $5 \mathrm{hr}$ & 5 & 5 & 5 & 5 & 5 & 5 & 4 & 4 & 4 & 3 & 3 \\
\hline \multirow{4}{*}{ Kota Kinabalu } & Max. & $30^{\circ} \mathrm{C}$ & 30 & 31 & 32 & 32 & 31 & 31 & 31 & 31 & 31 & 31 & 31 \\
\hline & Min. & $23^{\circ} \mathrm{C}$ & 23 & 23 & 24 & 24 & 24 & 24 & 24 & 23 & 23 & 23 & 23 \\
\hline & Rain & $133 \mathrm{~mm}$ & 63 & 71 & 124 & 218 & 311 & 277 & 256 & 314 & 334 & 296 & 241 \\
\hline & Sun & $6 \mathrm{hr}$ & 7 & 8 & 8 & 7 & 7 & 7 & 6 & 6 & 6 & 6 & 6 \\
\hline \multirow{4}{*}{ Kuching } & Max. & $30^{\circ} \mathrm{C}$ & 30 & 31 & 32 & 33 & 33 & 32 & 33 & 32 & 32 & 31 & 31 \\
\hline & Min. & $23^{\circ} \mathrm{C}$ & 23 & 23 & 23 & 23 & 23 & 23 & 23 & 23 & 23 & 23 & 23 \\
\hline & Rain & $683 \mathrm{~mm}$ & 522 & 339 & 286 & 253 & 199 & 199 & 211 & 271 & 326 & 343 & 465 \\
\hline & Sun & $4 \mathrm{hr}$ & 4 & 4 & 5 & 6 & 6 & 6 & 6 & 5 & 5 & 5 & 4 \\
\hline
\end{tabular}

and the most suitable function that fits the drawn data should be found. Figure 2 shows regression curves of daily diffuse ratio for four individual international sites.

The recommended equation which fits the shown relations is proposed by [37] as follows:

$$
\frac{E_{D}}{E_{T}}=0.962+0.779 K_{T}-4.375 K_{T}{ }^{2}+2.716 K_{T}{ }^{3} .
$$

In this paper, a new equation for calculating $E_{D}$ using the collected data is derived instead of using (8), for accuracy purposes. Figure 3 show regression curves of daily diffuse ratio for five different locations in Malaysia.

Equation (9) was derived from Figure 3; however, using (9) to calculate $E_{D}$ in Malaysia, or in nearby locations, is more accurate than using (8):

$$
\frac{E_{D}}{E_{T}}=0.9505+0.91634 K_{T}-4.851 K_{T}^{2}+3.2353 K_{T}{ }^{3} .
$$

After finding $E_{T}$ and $E_{D}, E_{B}$ can be calculated using (5). 


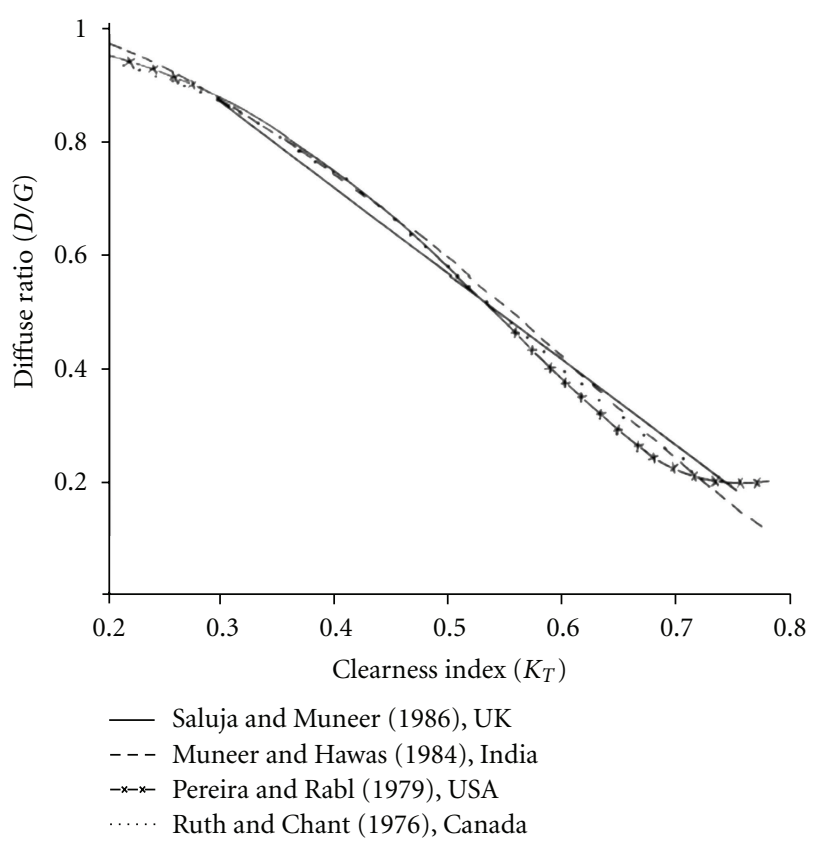

Figure 2: Regression curves of daily diffuse ratio-worldwide locations [37].

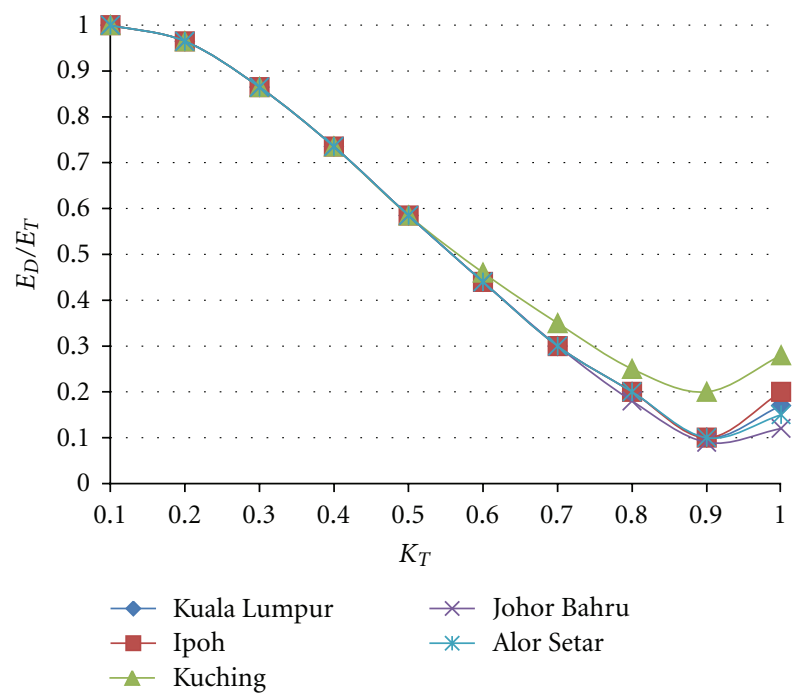

FIGURE 3: Regression curves of daily diffuse ratio-Malaysia.

Based on the mentioned equations, the calculation of solar radiations starts with predicting the clearness index $\left(K_{T}\right)$; therefore, a prediction for $K_{T}$ using ANNs was completed, as detailed in the next section.

\section{Artificial Neural Network for Clearness Index Prediction}

Artificial neural networks (ANNs) are information processing systems that are nonalgorithmic, nondigital, and intensely parallel [38]. They learn the relationship between the input and output variables by studying previously recorded data.

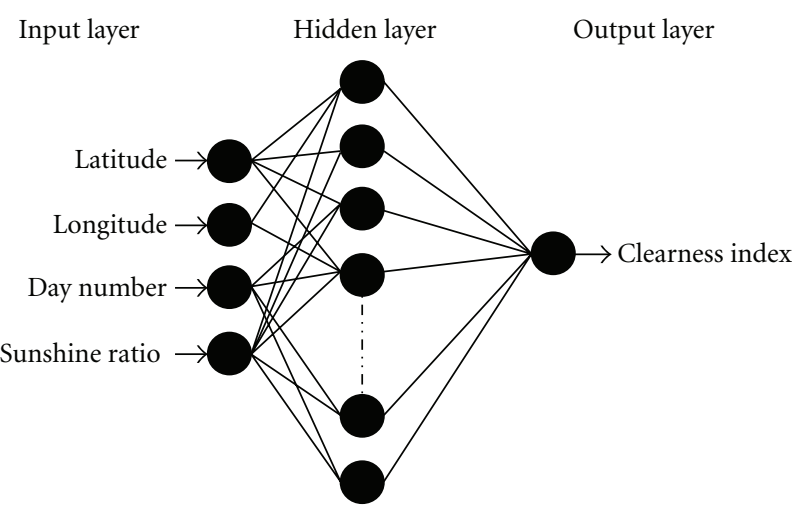

Figure 4: Topology of the FFMLP ANN used to predict the clearness index.

An ANN resembles a biological neural system, composed of layers of parallel elemental units called neurons. The neurons are connected by a large number of weighted links, over which signals or information can pass. A neuron receives inputs over its incoming connections, combines the inputs, generally performs a nonlinear operation, and outputs the final results. MATLAB was used to train and develop the ANNs for clearness index prediction. The neural network adopted was a feed forward, multilayer perception (FFMLP) network, among the most commonly used neural networks that learn from examples. A schematic diagram of the basic architecture is shown in Figure 4. The network has three layers: the input, hidden, and output layers. Each layer is interconnected by connection strengths, called weights.

Four geographical and climatic variables were used as input parameters for the input nodes of the input layer. These variables were the day number, latitude, longitude, and daily sunshine hours ratio (i.e., measured sunshine duration over daily maximum possible sunshine duration). A single node was at the output layer with the estimated daily clearness index prediction as the output. The transfer function adopted for the neurons was a logistic sigmoid function $f\left(z_{i}\right)$ :

$$
\begin{gathered}
f\left(z_{i}\right)=\frac{1}{1+e^{-z_{i}}}, \\
z_{i}=\sum_{j=1}^{4} w_{i j} x_{j}+\beta_{i},
\end{gathered}
$$

where $z_{i}$ is the weighted sum of the inputs, $x_{j}$ is the incoming signal from the jth neuron (at the input layer), $w_{i j}$ the weight on the connection directed from neuron $j$ to neuron $i$ (at the hidden layer), and $\beta_{i}$ the bias of neuron $i$. Neural networks learn to solve a problem rather than being programmed to do so. Learning is achieved through training. In other words, training is the procedure by which the networks learn, and learning is the end result. The most common methodology was used, supervised training. Measured daily clearness index data were given, and the network learned by comparing the measured data with the estimated output. The difference (i.e., an error) is propagated backward (using a backpropagation training algorithm) from the output layer, 
TABle 2: Annual global solar radiation averages for five different sites in Malaysia.

\begin{tabular}{lcc}
\hline Site & $\begin{array}{c}\text { Average } E_{T} \text { per annum } \\
\text { (Measured) }\left(\mathrm{KWh} / \mathrm{m}^{2}\right)\end{array}$ & $\begin{array}{c}\text { Average } E_{T} \text { per annum } \\
(\text { Predicted })\left(\mathrm{KWh} / \mathrm{m}^{2}\right)\end{array}$ \\
\hline Kuala Lumpur & 4.84 & 4.83 \\
Johor Bahru & 4.51 & 4.55 \\
Ipoh & 4.54 & 4.64 \\
Alor Setar & 4.66 & 4.8 \\
Kuching & 4.62 & 4.66 \\
\hline
\end{tabular}

via the hidden layer, to the input layer, and the weights on the interconnections between the neurons are updated as the error is back-propagated. A multilayer network can mathematically approximate any continuous multivariate function to any degree of accuracy, provided that a sufficient number of hidden neurons are available. Thus, instead of learning and generalizing the basic structure of the data, the network may learn irrelevant details of individual cases.

In this research, 28 weather stations' data were used, 23 stations' data were used to train the network, and 5 sites were used to test it.

\section{Results and Discussion}

To ensure the efficacy of the developed network, five main sites were chosen out of the 28 sited in Malaysia. The chosen sites are Kuala Lumpur, Ipoh, Alor Setar, Kuching, and Johor Bahru. These sites span Malaysia and have been chosen to check the efficacy of the developed network over all of Malaysia.

The developed software first predicts the daily clearness index, then calculates the predicted global radiation based on (6), and finally the diffused radiation is calculated by (9).

5.1. Daily Solar Radiation Prediction. Figure 5 shows the predicted clearness indexes compared with the measured values for the five chosen stations. The figure shows good agreement between the measurements and the predictions. The best fit appears in the Johor Bahru and Kuching stations, while the worst is in the Alor Setar station. The fittings are all acceptable due to the low calculated error, as will be discussed in Section 5.3.

To evaluate the developed network, the measured values of the sunshine ratio for the year 2000 in each of the chosen sites have been used to predict the global and diffused solar radiation for this year. The predicted and estimated data were then compared with the measured data, which were also taken from the chosen sites for the same year. Figure 6 shows a comparison between the measured and predicted daily global solar radiation of the chosen sites.

In general, the prediction of the global radiation was acceptable and accurate. Based on the results, it is clear that Malaysia has a stable climate throughout the year. Cloud cover generally reduces the radiation by $50 \%$, so the global irradiation fluctuated in the range of 2 to $6 \mathrm{KWh} / \mathrm{m}^{2}$. The second part of the year (October to February) saw more cloud cover, and consequently, poorer solar potential compared with the first part of the year (March to October). Table 2 shows the yearly average global solar irradiation for the five sites. From the table, the best prediction is at Kuala Lumpur station, while the worst is at Alor Setar. Kuala Lumpur region has the highest solar potential.

Figure 7 shows a comparison between the measured and predicted diffused solar irradiation.

The estimation of the diffused solar irradiation was evaluated using (9). In general, the estimation was acceptable. Table 4 shows the yearly average diffused solar irradiation for the five sites. Table 3 shows a comparison of the annual average of the diffused solar radiation estimated by the proposed equation (9) and estimated by the equation proposed by Caudill and Butler in [38] (8). The proposed equation showed better accuracy in the estimation.

5.2. Monthly Solar Irradiation. To get an idea of the monthly solar irradiation profile in Malaysia, the chosen five sites' weather data were used again to predict the daily global and diffused solar irradiations at the five sites for five years (1999-2004). The monthly average global and diffused solar irradiations were then calculated and compared with the monthly averages of the measured data. Figure 8 shows the monthly average of the predicted global solar irradiations compared with the measured values.

As mentioned previously and also from Figure 8, the global solar irradiation values were clearly degraded in the wet season (October to February) due to the heavy cloud cover and rains; however, most of the monthly averages of $E_{T}$ at all stations fluctuated in the range of $3.5-5.5 \mathrm{KWh} / \mathrm{m}^{2}$. Figure 9 shows the monthly average of the estimated diffused solar irradiation compared with the measured values. Figure 9 also shows a comparison of the diffused solar radiation values which were estimated by (8) with the values which were estimated by (9).

From Figure 9, using the proposed (8) to estimate $E_{D}$ is better than using (9), proposed by Caudill and Butler in [38]. The estimation of $E_{D}$ was not as accurate as the prediction of $E_{T}$, but knowing $E_{T}$ accurately is more important for the design of photovoltaic power systems because these systems are designed based on global radiation not diffused. But in cause of solar water heaters (SWH), obtaining an accurate estimation regarding the diffused irradiation is important because SWH systems can only work by direct irradiation.

5.3. Developed ANN Evaluation. As mentioned above, predicted values (daily global and diffused irradiations) have been compared with measured values to calculate the mean absolute percentage error (MAPE). The MAPE is defined as

$$
\text { MAPE }=\frac{\text { Measured Value }- \text { Predicted Value }}{\text { Measured Value }} \times 100 \% .
$$

The MAPE values of the chosen sites are listed in Table 4 . The average error in predicting the global solar irradiation was $5.86 \%$. As for the error in estimating the diffused solar irradiation, the proposed equation has an average error of 


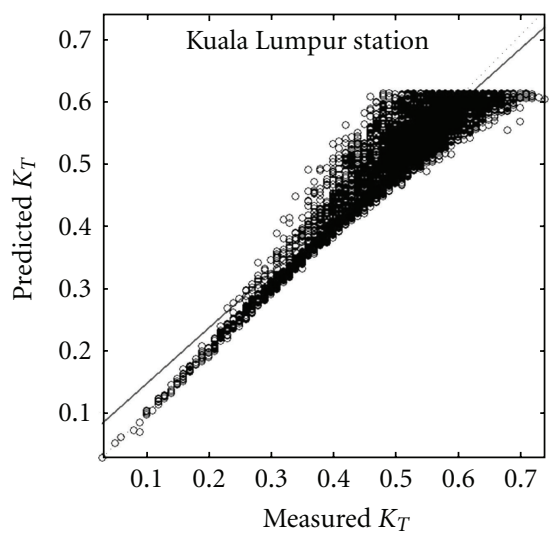

(a)

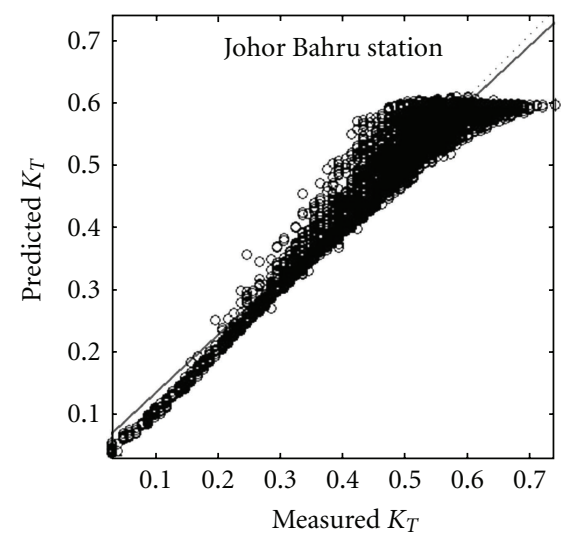

(b)

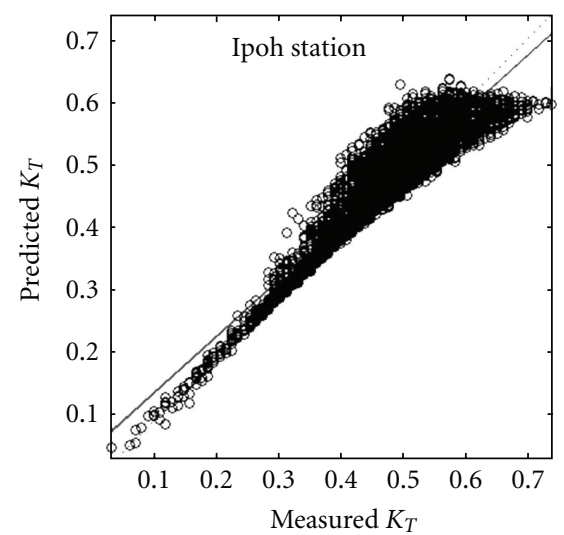

(c)
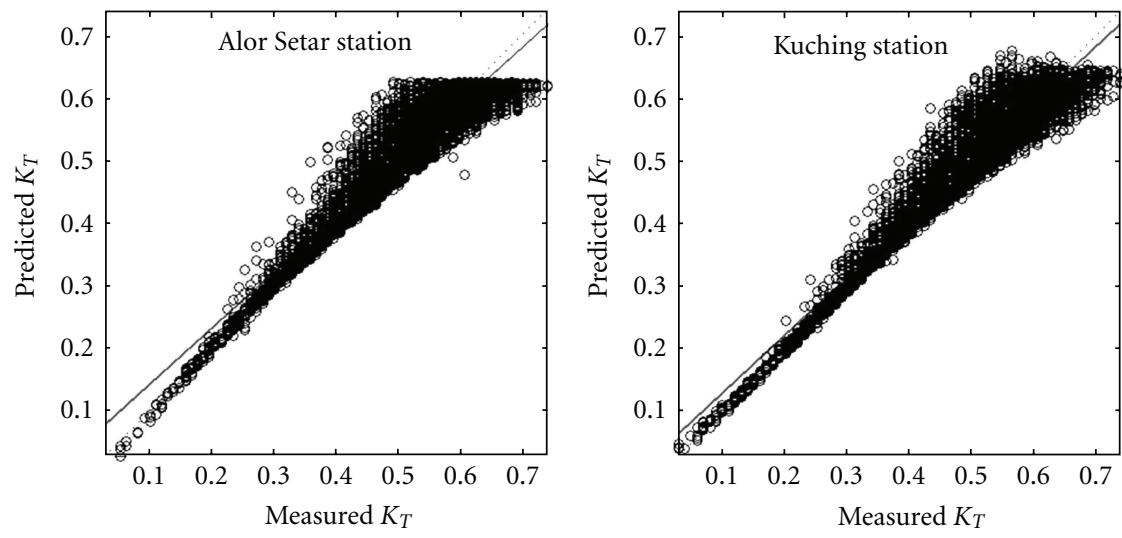

- Data

$\longrightarrow \quad$ Fit

(d)

(e)

FIgURE 5: Comparison between measured and predicted clearness indexes.

TABLE 3: Annual global solar radiation averages for five different sites in Malaysia.

\begin{tabular}{lccc}
\hline Site & $\begin{array}{c}\text { Average } E_{D} \text { per annum } \\
\text { (Measured) }\left(\mathrm{KWh} / \mathrm{m}^{2}\right)\end{array}$ & $\begin{array}{c}\text { Average } E_{D} \text { per annum } \\
\text { Estimated using }(9)) \\
\left(\mathrm{KWh} / \mathrm{m}^{2}\right)\end{array}$ & $\begin{array}{c}\text { Average } E_{D} \text { per annum } \\
(\text { Estimated using }(8)) \\
\left(\mathrm{KWh} / \mathrm{m}^{2}\right)\end{array}$ \\
\hline Kuala Lumpur & 2.81 & 2.81 & 2.85 \\
Johor Bahru & 2.82 & 2.81 & 2.79 \\
Ipoh & 2.86 & 2.8 & 2.77 \\
Alor Setar & 2.8 & 2.7 & 2.66 \\
Kuching & 2.83 & 2.82 & 2.29 \\
\hline
\end{tabular}

TABLE 4: MAPE in global and diffused solar irradiation.

\begin{tabular}{lccc}
\hline Site & MAPE in $E_{T}$ & MAPE in $E_{D}$ using $(8)$ & MAPE in $E_{D}$ using $(9)$ \\
\hline Kuala Lumpur & $5.5 \%$ & $10.5 \%$ & $9.6 \%$ \\
Alor Setar & $7 \%$ & $11.7 \%$ & $11.5 \%$ \\
Johor Bahru & $5.2 \%$ & $8.5 \%$ & $8.7 \%$ \\
Kuching & $5.5 \%$ & $9.5 \%$ & $9.3 \%$ \\
Ipoh & $6.4 \%$ & $10.2 \%$ & $10 \%$ \\
\hline
\end{tabular}



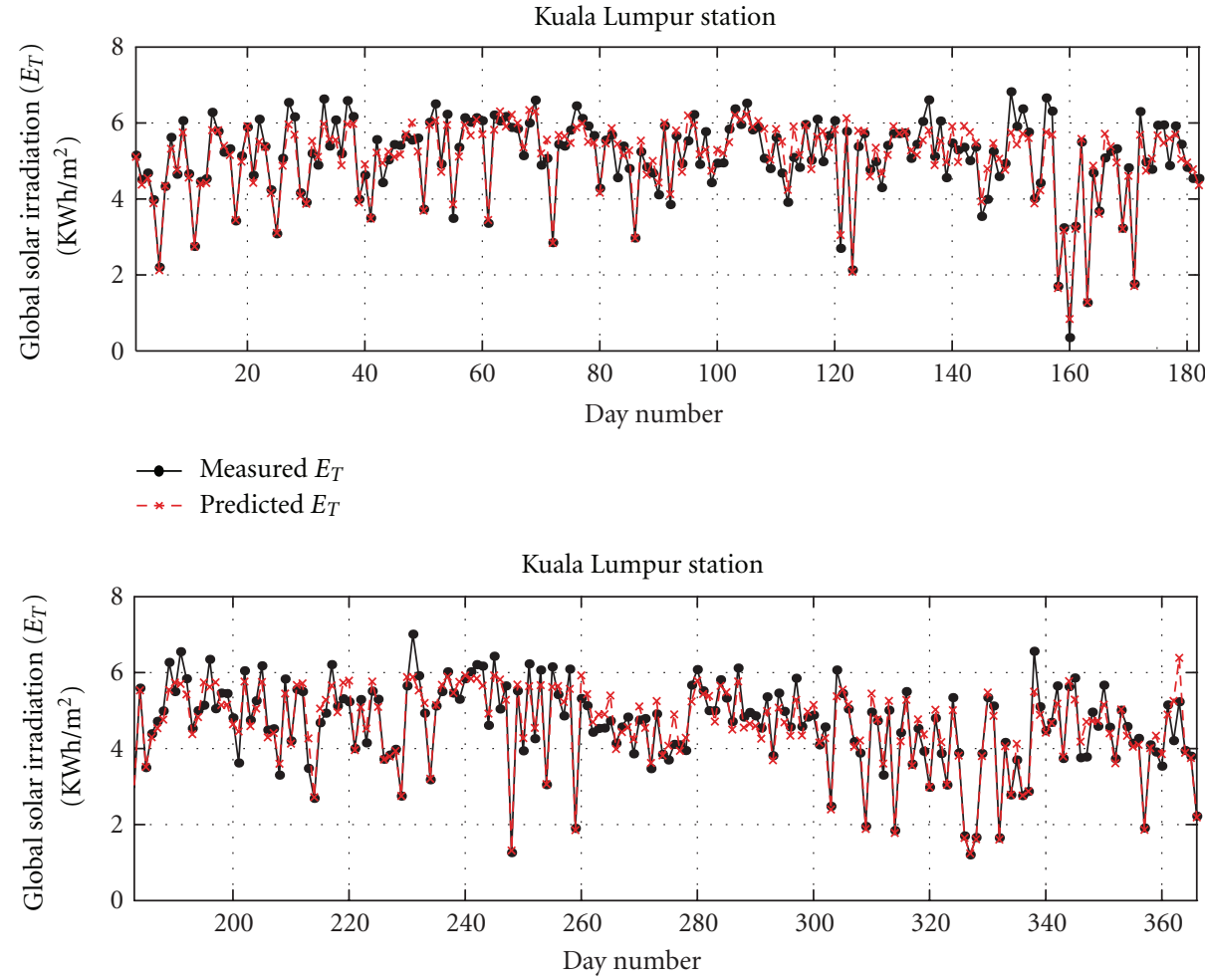

- Measured $E_{T}$

-* - Predicted $E_{T}$

(a)

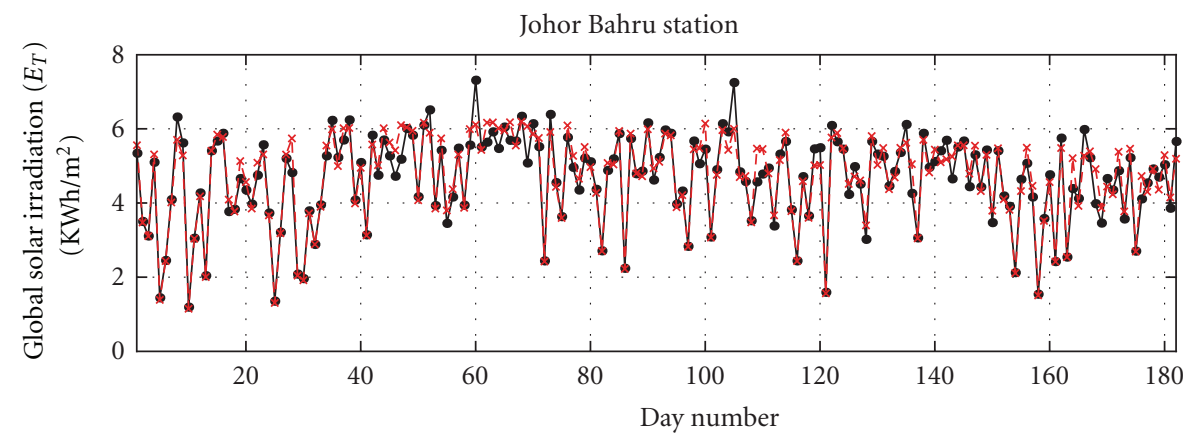

$\rightarrow$ Measured $E_{T}$

-* - Predicted $E_{T}$

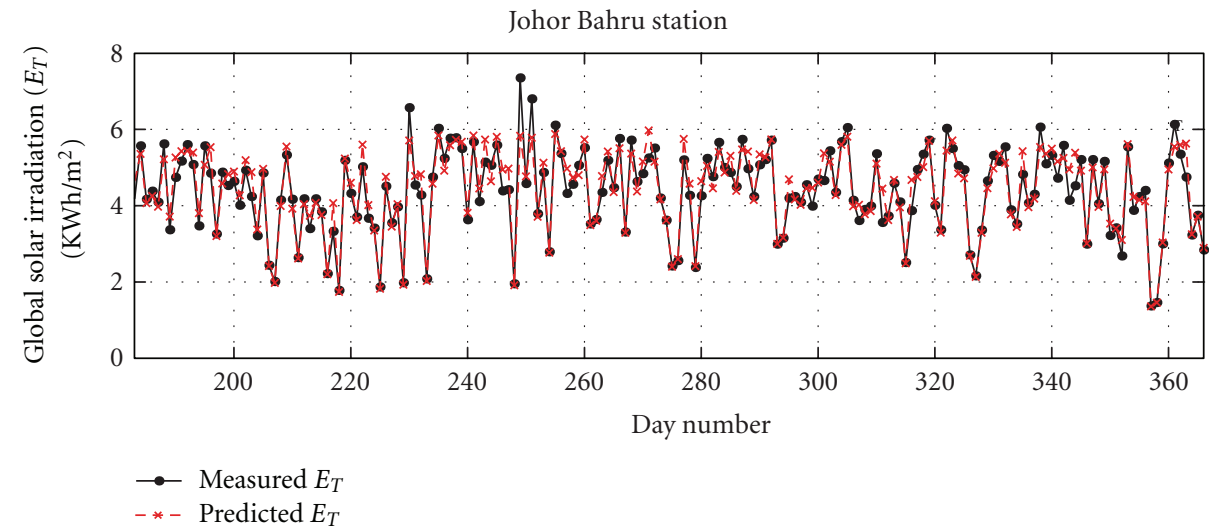

(b)

FIgURe 6: Continued. 


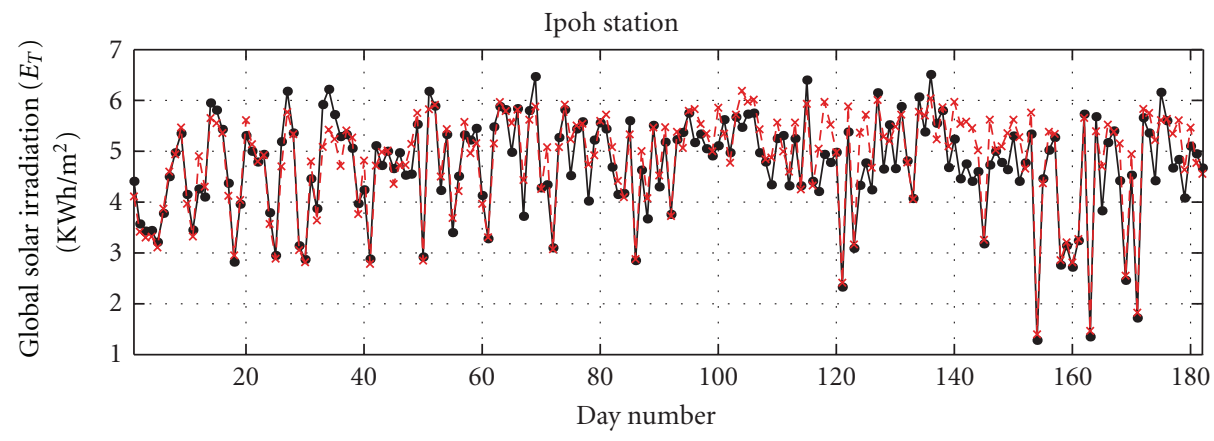

$\rightarrow$ Measured $E_{T}$

-* - Predicted $E_{T}$

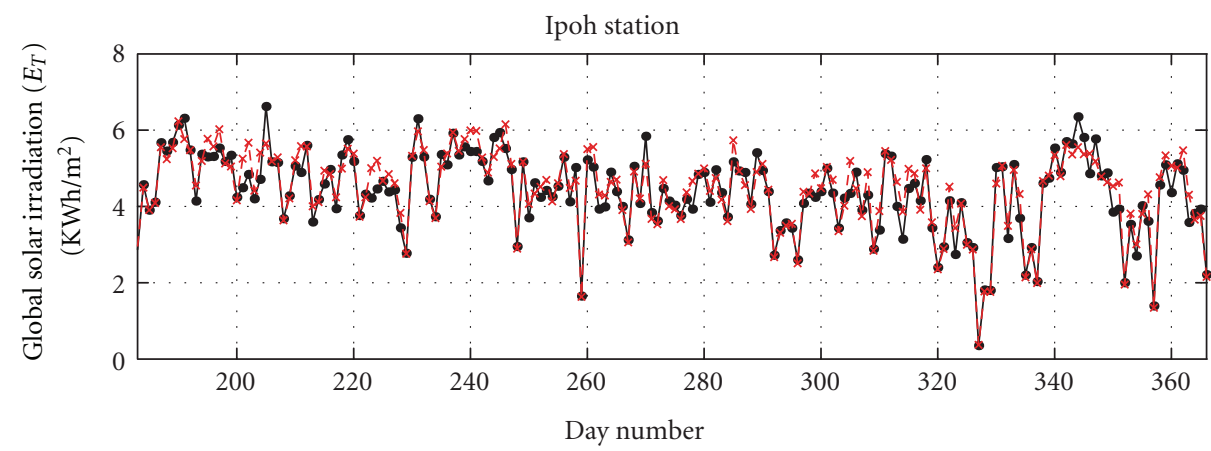

$\rightarrow$ Measured $E_{T}$

-* - Predicted $E_{T}$

(c)

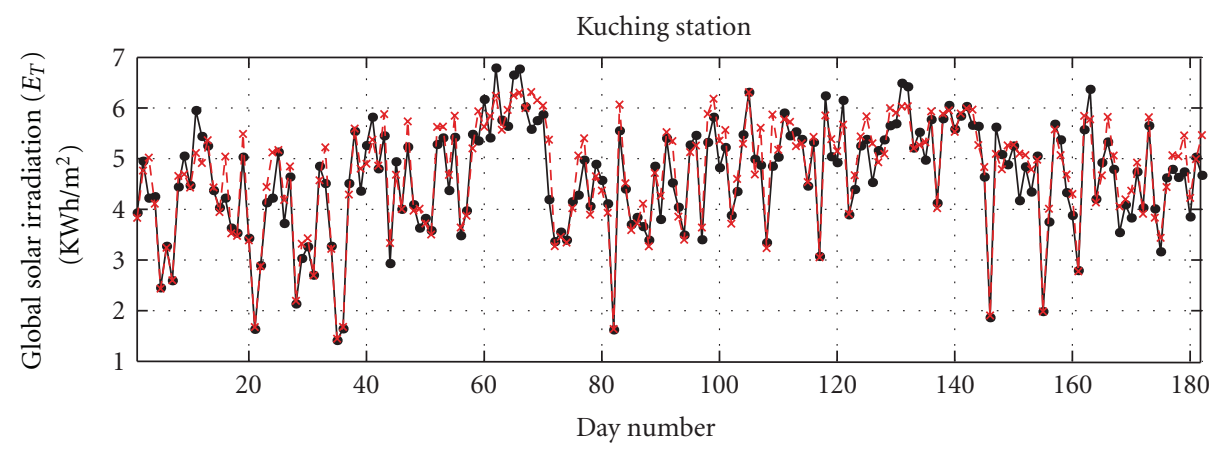

- Measured $E_{T}$

-* Predicted $E_{T}$

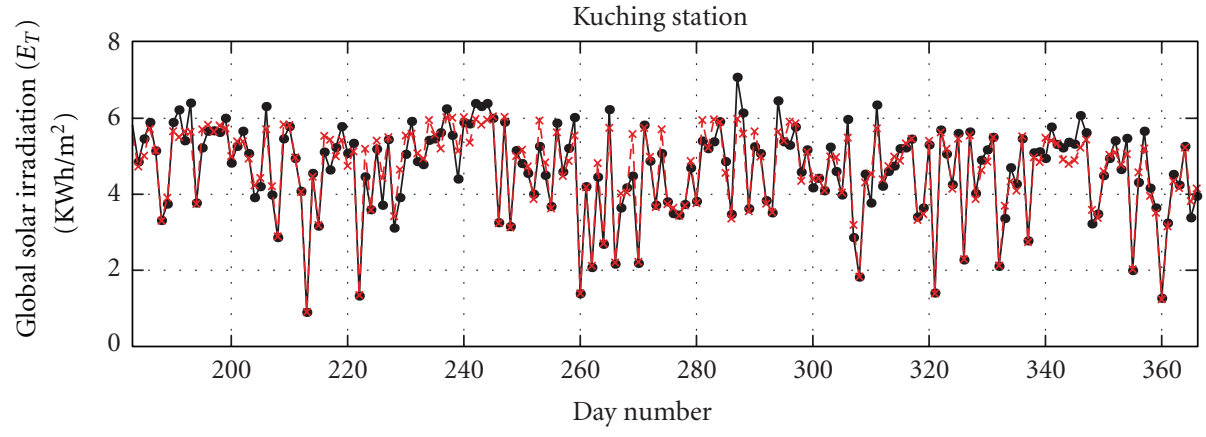

$\rightarrow$ Measured $E_{T}$

-* - Predicted $E_{T}$

(d)

FIgURE 6: Continued. 

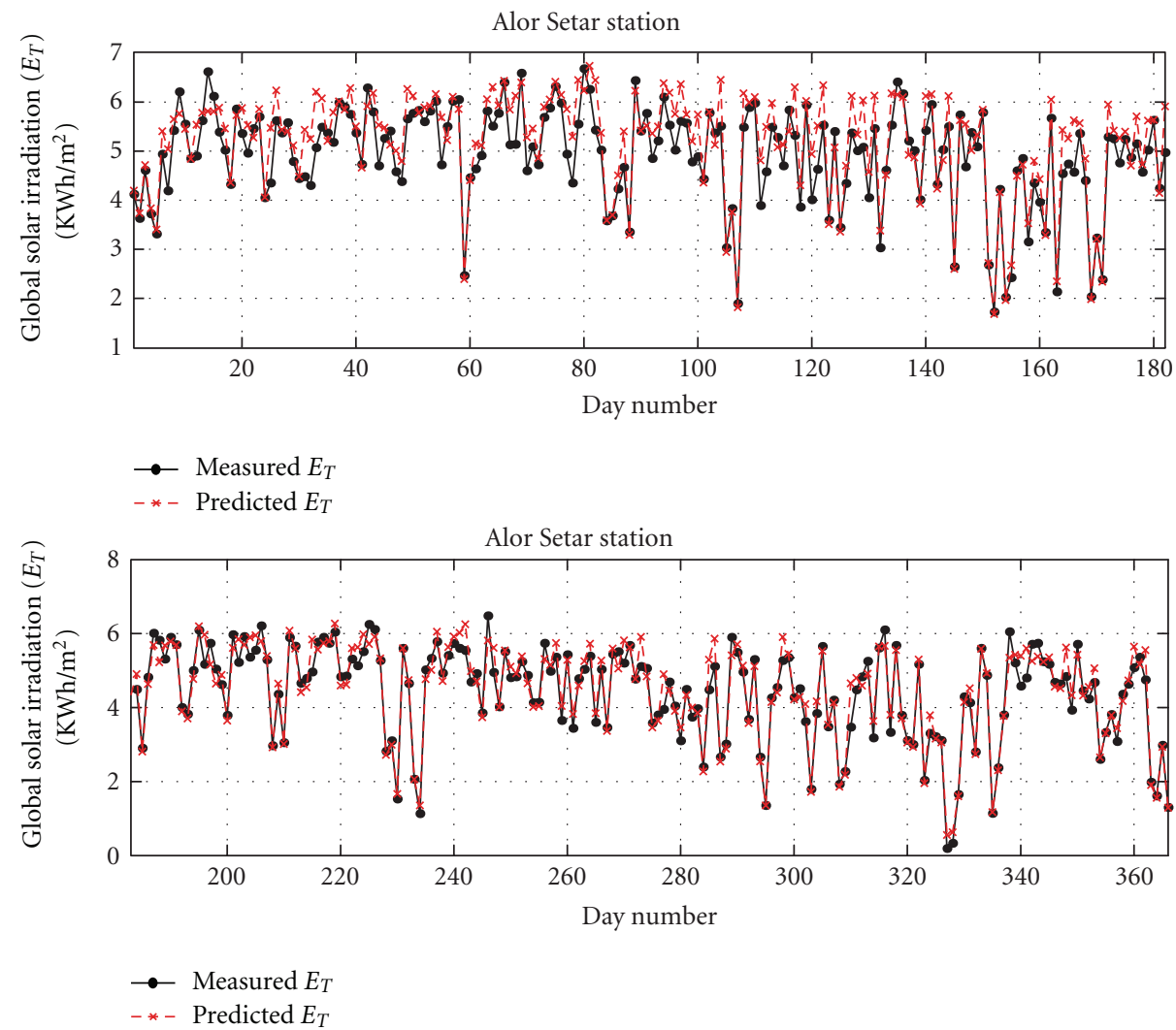

(e)

FIGURE 6: Comparison between the measured and predicted daily global radiation for the chosen five sites.

$9.8 \%$, while the error in estimating the diffused solar irradiation using (8) was $10.1 \%$. Thus, a slight error reduction is achieved by using (9) instead of (8) for the estimation of diffused solar irradiation in Malaysia and nearby regions.

Additionally, most authors who have worked in this field evaluated the performance of the utilized ANN models quantitatively and ascertained whether there is any underlying trend in the performance of the ANN models in different climates using statistical analysis involving mean bias error (MBE) and root mean square error (RMSE). These statistics were determined as

$$
\begin{aligned}
\mathrm{MBE} & =\frac{1}{n} \sum_{i=1}^{n}\left(I_{P_{i}}-I_{i}\right), \\
\mathrm{RMSE} & =\sqrt{\frac{1}{n} \sum_{i=1}^{n}\left(I_{P_{i}}-I_{i}\right)^{2},}
\end{aligned}
$$

where $I_{P i}$ is the predicted daily global irradiation on a horizontal surface, $I_{i}$ is the measured daily global radiation on a horizontal surface, and $n$ is the number of observations.

$\mathrm{MBE}$ is an indication of the average deviation of the predicted values from the corresponding measured data and can provide information for the long-term performance of the models. A positive MBE value indicates the amount of overestimation in the predicted global solar radiation and vice versa. RMSE provides information on the short-term performance and is a measure of the variation of the predicted values around the measured data, indicated by the scattering of data around the linear lines shown in Figure 5. Table 5 shows the MBE and RMSE values for the chosen sites.

From Table 6, the MBE of the Kuala Lumpur station was $-0.18 \%$, meaning that the predicted values are underestimated by $0.018 \%$, while every others station showed a slight overestimation. The average MBE for the developed network is $0.673 \mathrm{KWh} / \mathrm{m}^{2}$, meaning the predicted values were overestimated by $1.46 \%$.

The RMSE shows the efficiency of the developed network in predicting future individual values. A large positive RMSE means a large deviation in the predicted value from the real value. The average RMSE for the developed network is 0.3684 $\mathrm{KWh} / \mathrm{m}^{2}$, meaning a deviation of $7.96 \%$ is possible in a predicted individual value. Table 6 shows a comparison between the proposed network and other proposed networks, the comparison is made based on the MAPE, MBE, RMSE, number of network inputs, and the type of network.

\section{Conclusion}

A prediction of global solar irradiation using ANN is developed. This prediction was based on collected data from 

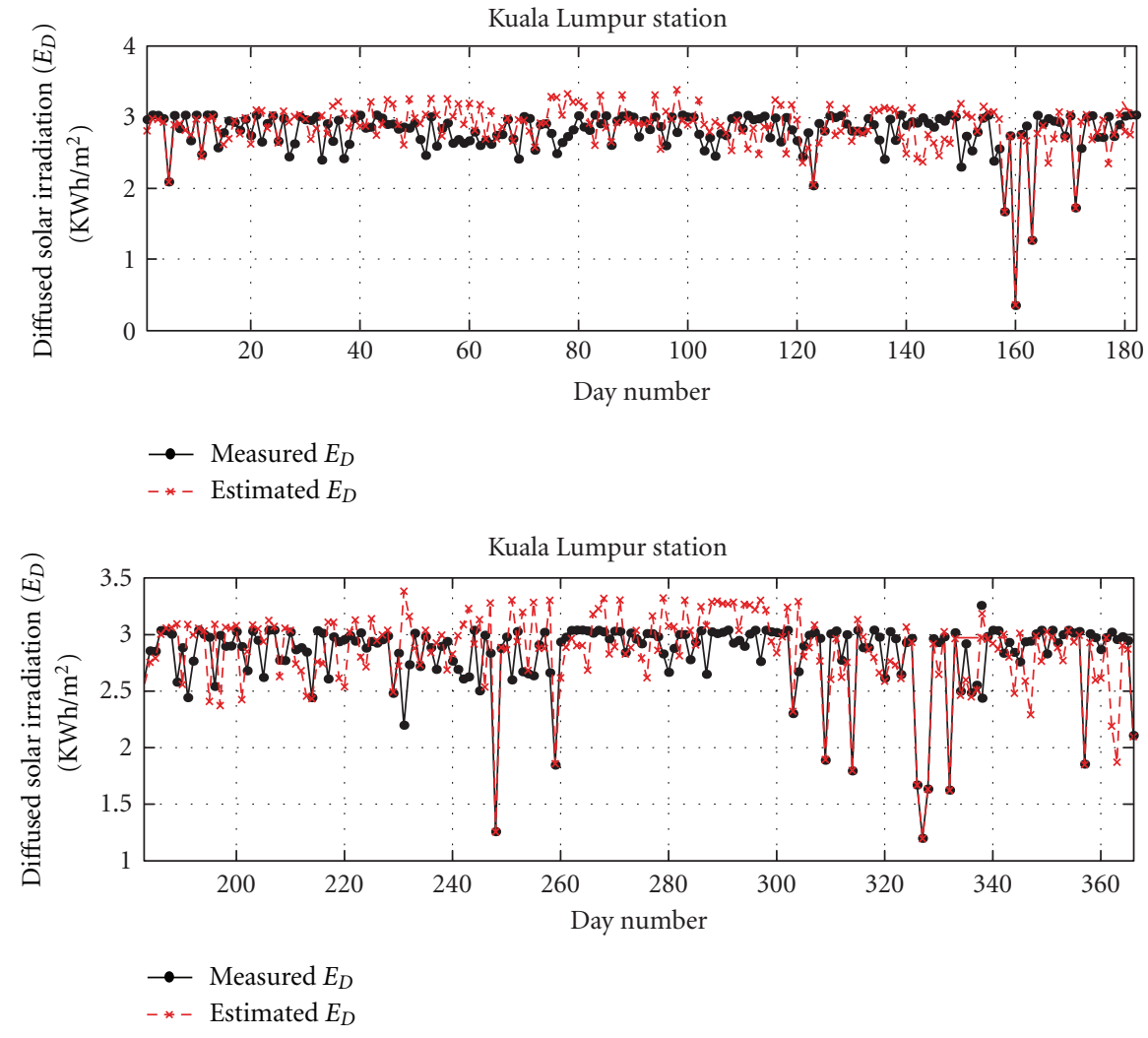

(a)
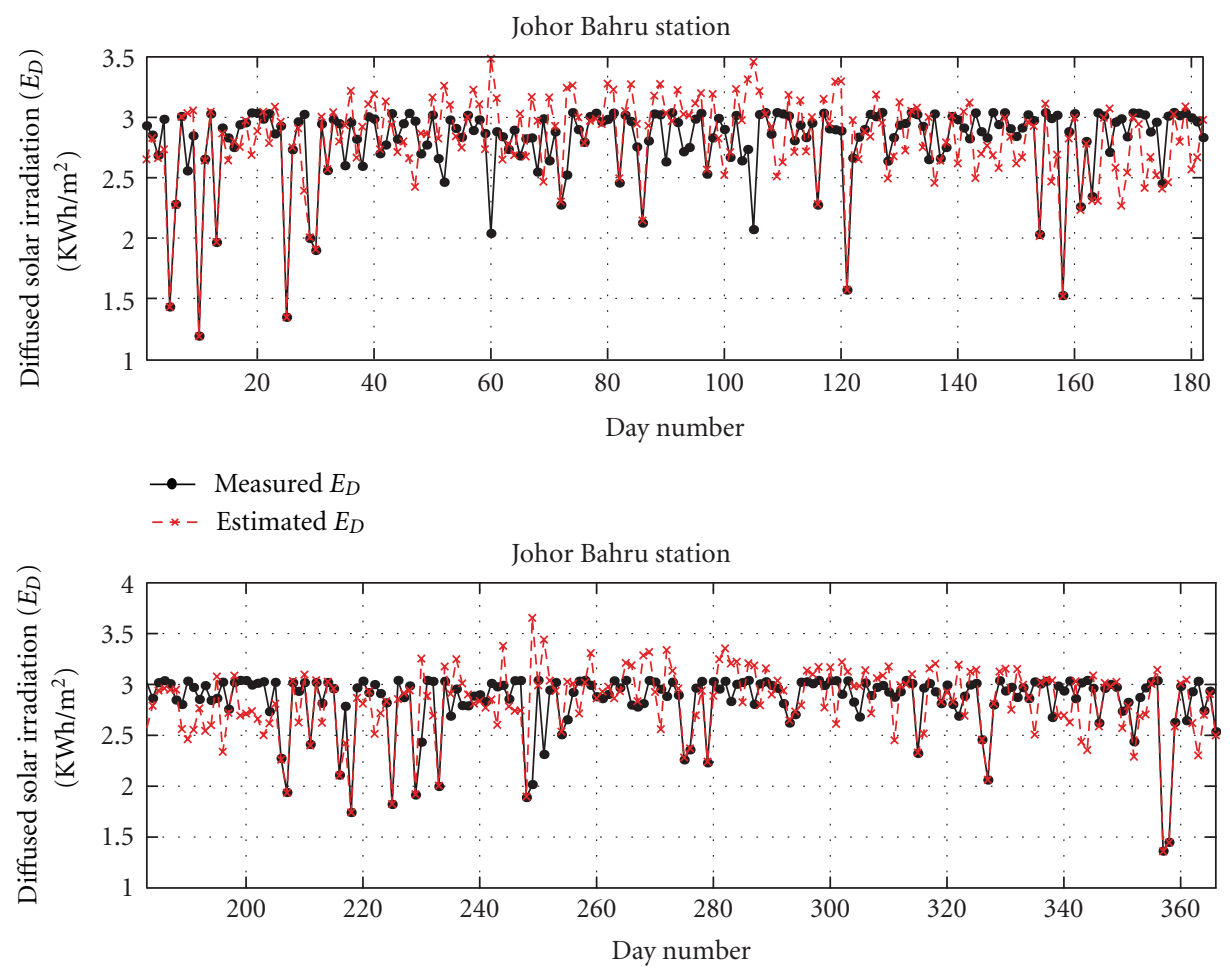

- Measured $E_{D}$

-* - Estimated $E_{D}$

(b)

Figure 7: Continued. 


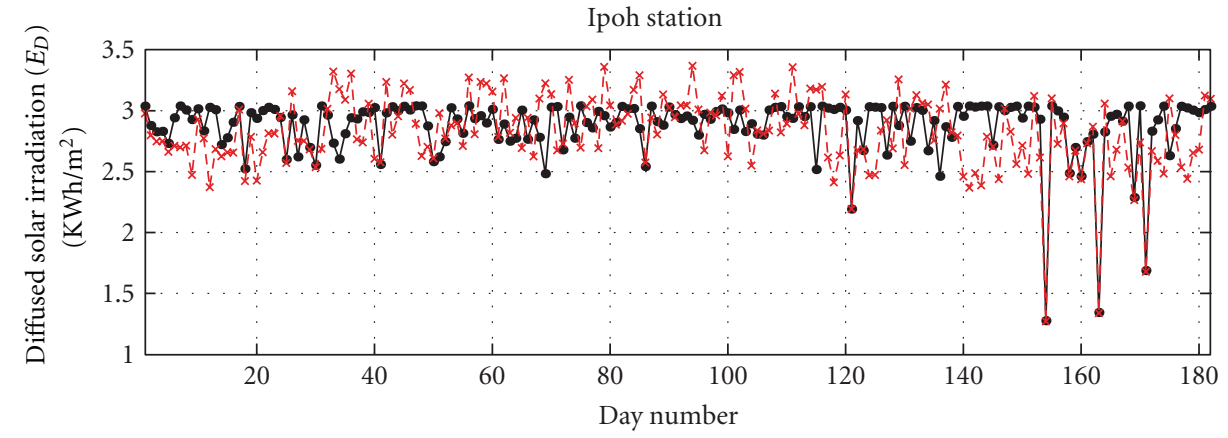

$\rightarrow$ Measured $E_{D}$

-* - Estimated $E_{D}$

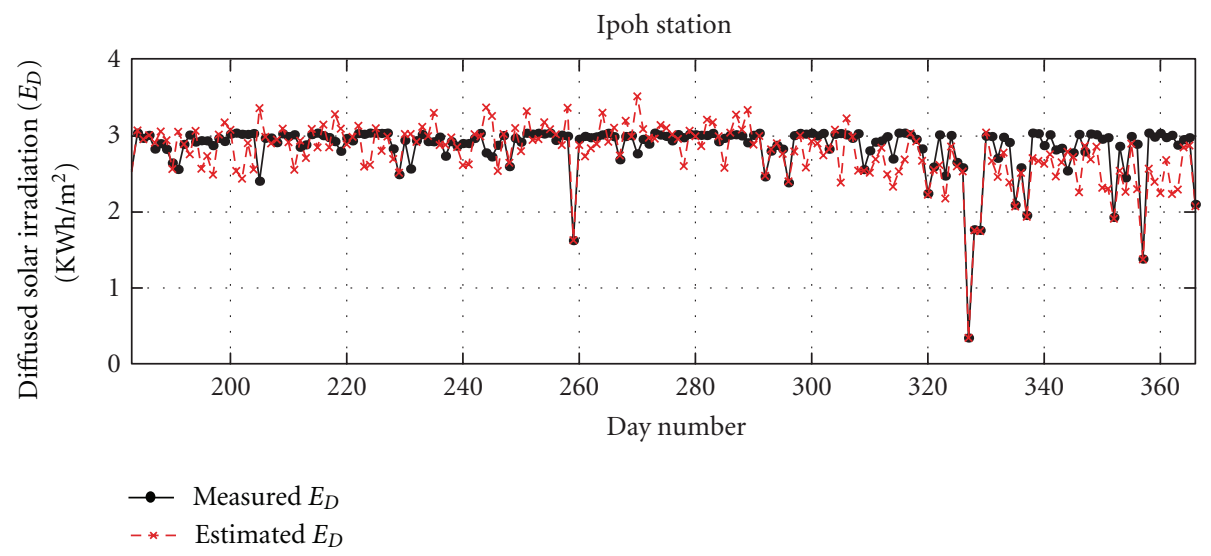

(c)

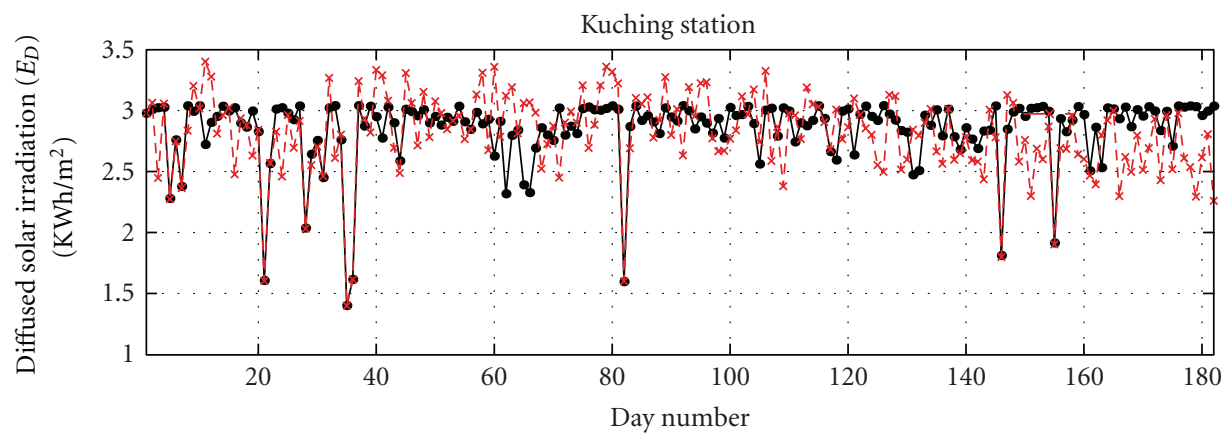

$\rightarrow$ Measured $E_{D}$

-* - Estimated $E_{D}$

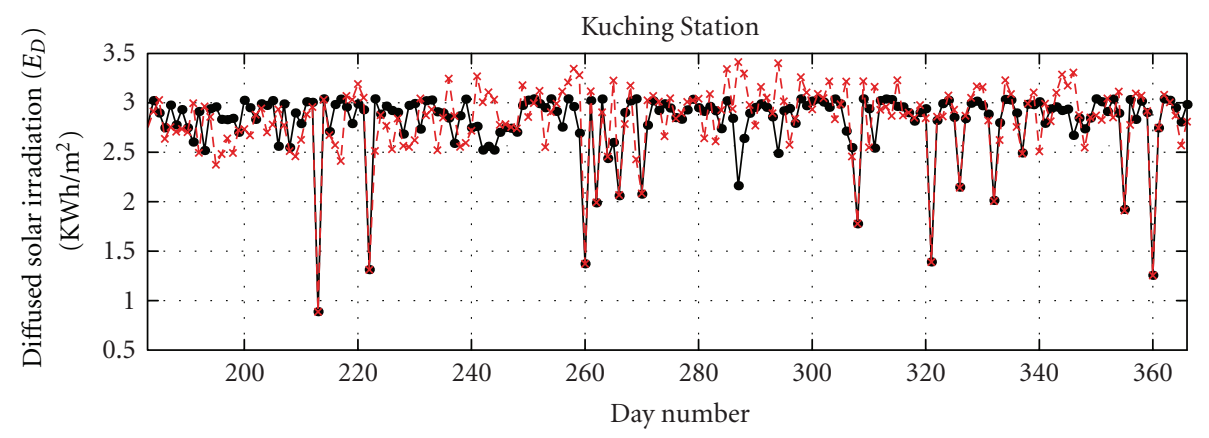

$\rightarrow$ Measured $E_{D}$

- * Estimated $E_{D}$

(d)

Figure 7: Continued. 

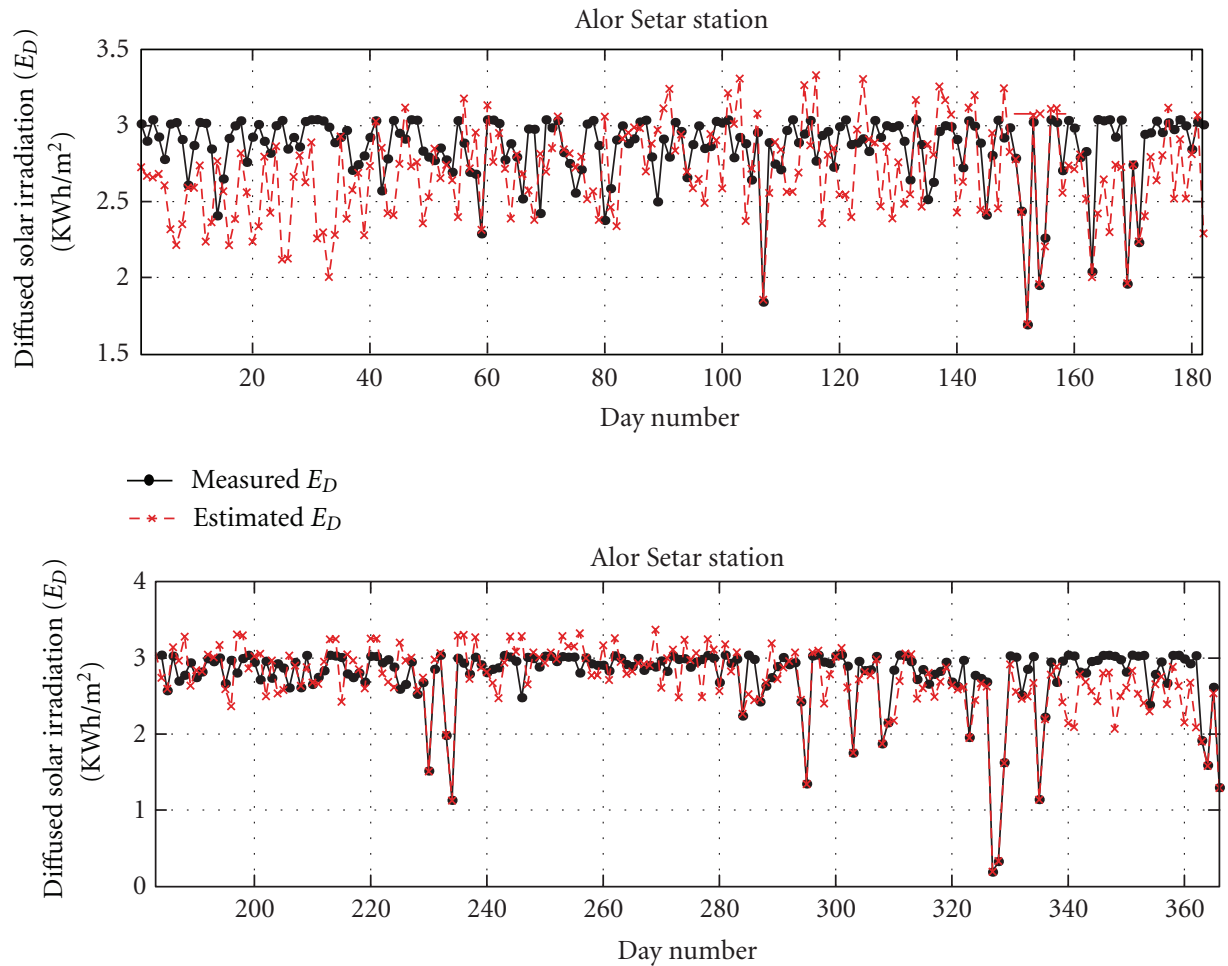

$\rightarrow$ Measured $E_{D}$

-* - Estimated $E_{D}$

(e)

FIgURE 7: Comparison between the measured and predicted diffused solar irradiation.

TABLE 5: MBE and RMSE for the five sites.

\begin{tabular}{lcccc}
\hline Site & MBE $\left(\mathrm{KWh} / \mathrm{m}^{2}\right)$ & MBE $(\%)$ & RMSE $\left(\mathrm{KWh} / \mathrm{m}^{2}\right)$ & 0.348 \\
Kuala Lumpur & -0.0087 & $-0.18 \%$ & 0.419 & \\
Alor Setar & 0.161 & $3.45 \%$ & 0.342 & $7.2 \%$ \\
Johor Bahru & 0.043 & $0.95 \%$ & 0.353 & $7.6 \%$ \\
Kuching & 0.036 & $0.78 \%$ & 0.380 & $7.6 \%$ \\
Ipoh & 0.105 & $2.3 \%$ & & $8.4 \%$ \\
\hline
\end{tabular}

TABLE 6: Comparison with previous work.

\begin{tabular}{|c|c|c|c|c|c|c|c|}
\hline Reference & MAPE (\%) & MBE $(\%)$ & RMSE (\%) & Number of inputs & Network topology & Number of used stations & Country \\
\hline$[6]$ & - & - & $6.5-19.1$ & 5 & FF; MLP & 10 & KSA \\
\hline [7] & 6.4 & - & - & 8 & FF; MLP & 2 & Oman \\
\hline Mihlakakou, [14] & - & - & $6.05-79.02$ & 7 & FF; MLP & 1 & Greece \\
\hline$[12]$ & - & - & $6.5-51.5$ & 7 & FF; MLP & 3 & Spain \\
\hline Atsu, 2002 & - & - & $5.4-49.9$ & 5 & FF; MLP & 8 & Oman \\
\hline$[26]$ & 6.78 & $2.84-3.3$ & - & 6 & FF; MLP & 12 & Turkey \\
\hline$[28]$ & 1.5 & - & - & 4 & FF; MLP & 1 & Algeria \\
\hline Elminir, [32] & 4.14 & $-0.71-1.9$ & - & 5 & FF; MLP & 3 & Egypt \\
\hline$[31]$ & - & $-1.28-.44$ & $1.65-2.79$ & 7 & FFBN & 11 & India \\
\hline Joseph, 2008 & - & $-16.9-18.6$ & $9.1-20.5$ & 6 & FF; MLP & 40 & China \\
\hline Proposed ANN & 5.92 & 1.46 & 7.96 & 4 & FF; MLP & 28 & Malaysia \\
\hline
\end{tabular}




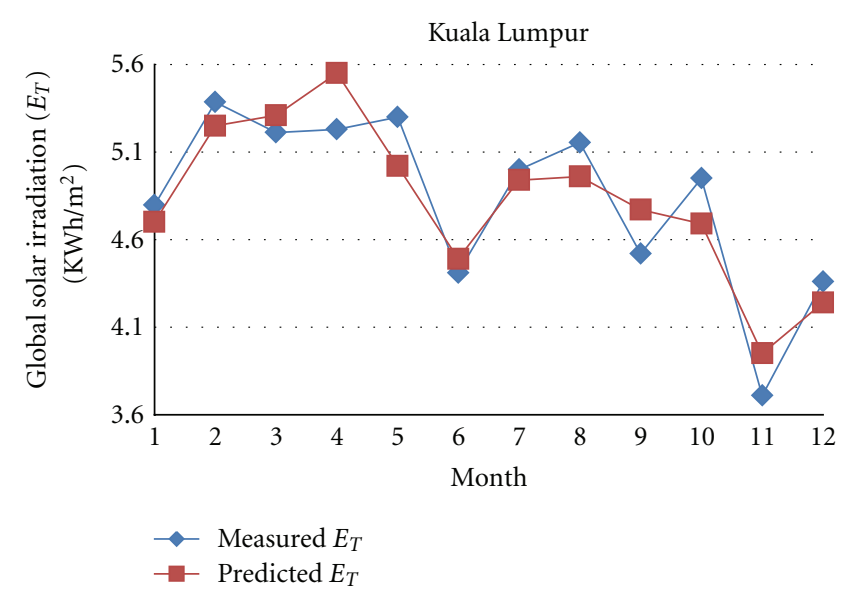

(a)

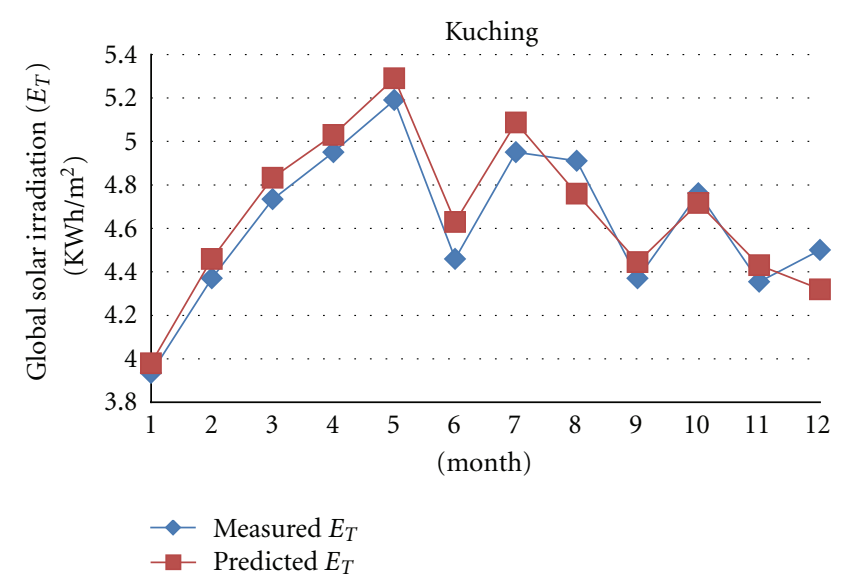

(c)

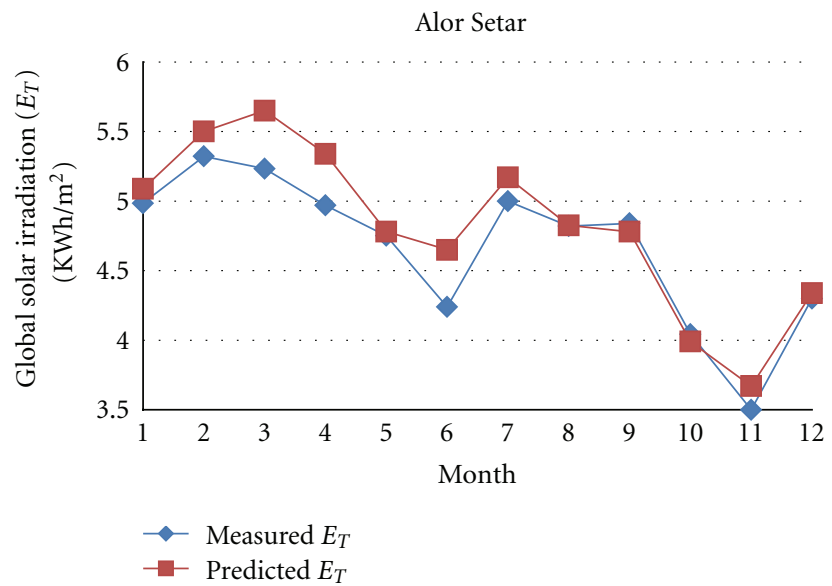

(b)

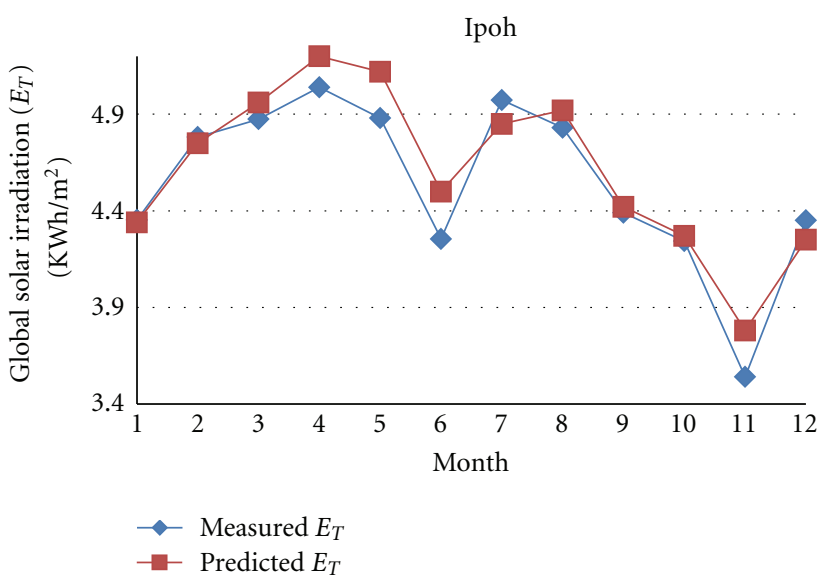

(d)

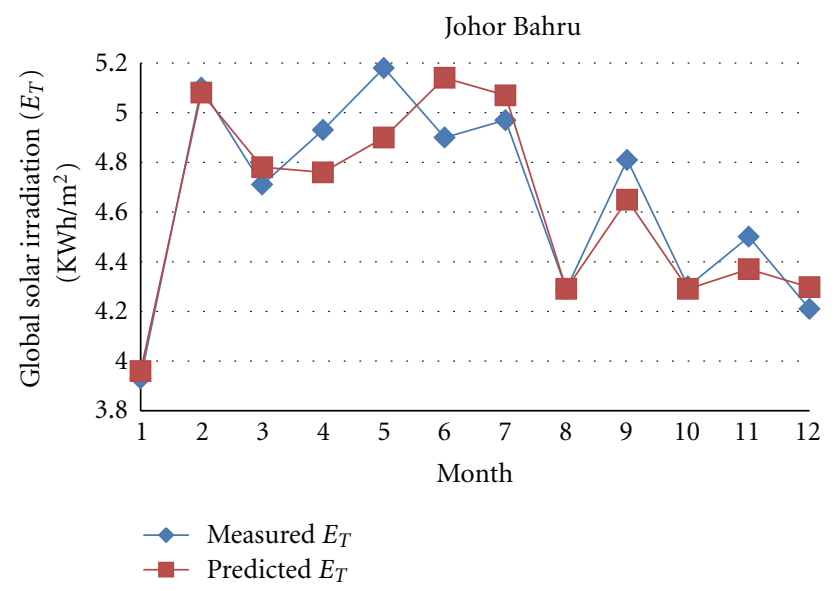

(e)

FIGURE 8: Comparison between the monthly average of the predicted and the measured global solar irradiations.

28 sites in Malaysia. The developed network predicted the clearness indexes. The clearness indexes were then used to predict the global solar irradiation. Additionally, estimations of the diffused solar radiation were proposed using an equation developed for Malaysia. This equation calculates the diffused solar irradiation as a function of the global solar irradiation and the clearness index. Five main sites in Malaysia have been used to test the proposed approach. The 
Kuala Lumpur

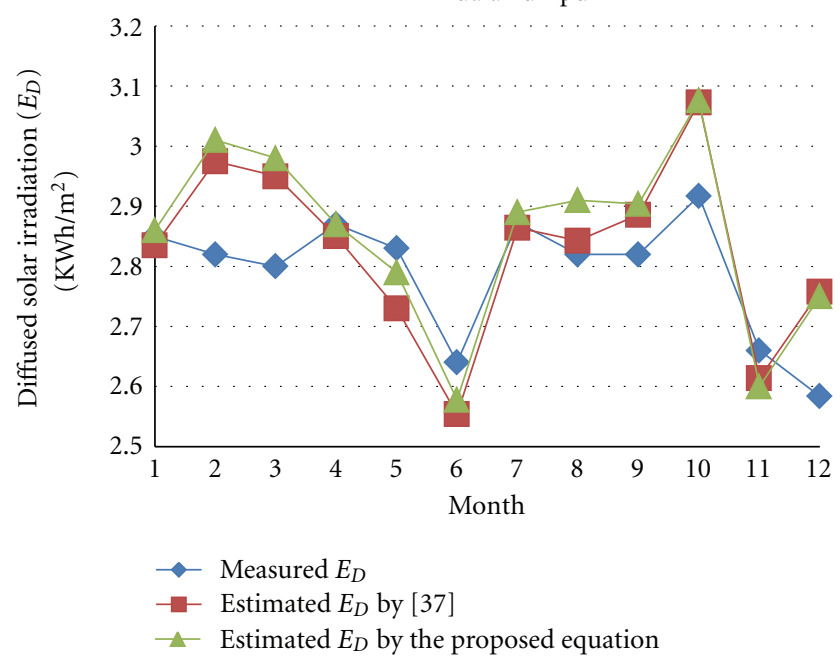

(a)

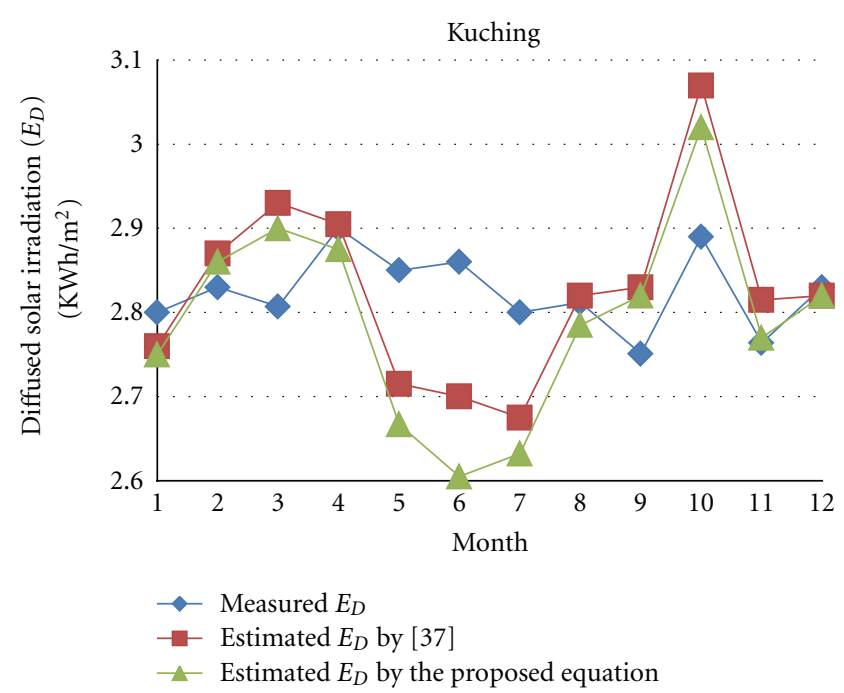

(c)

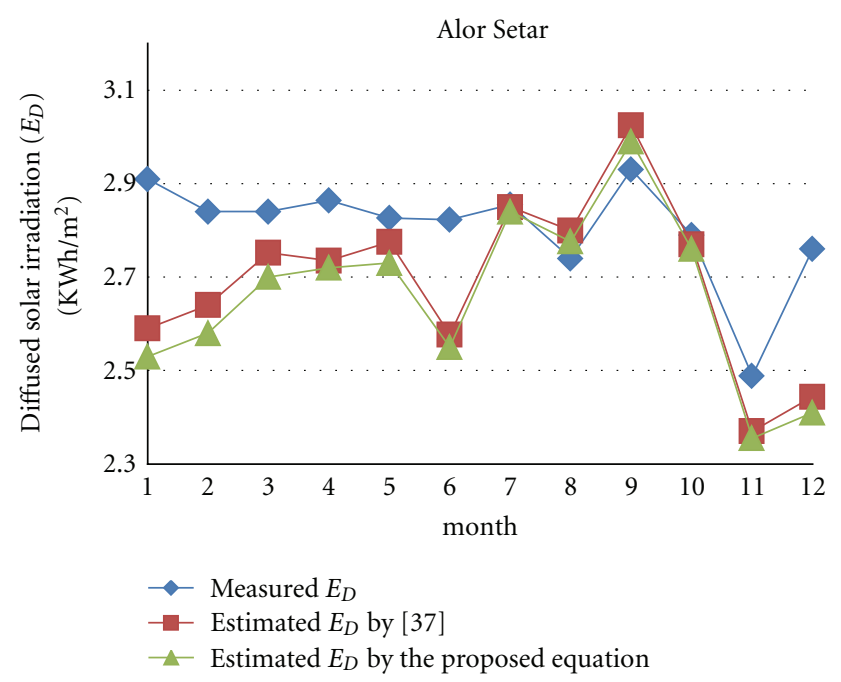

(b)

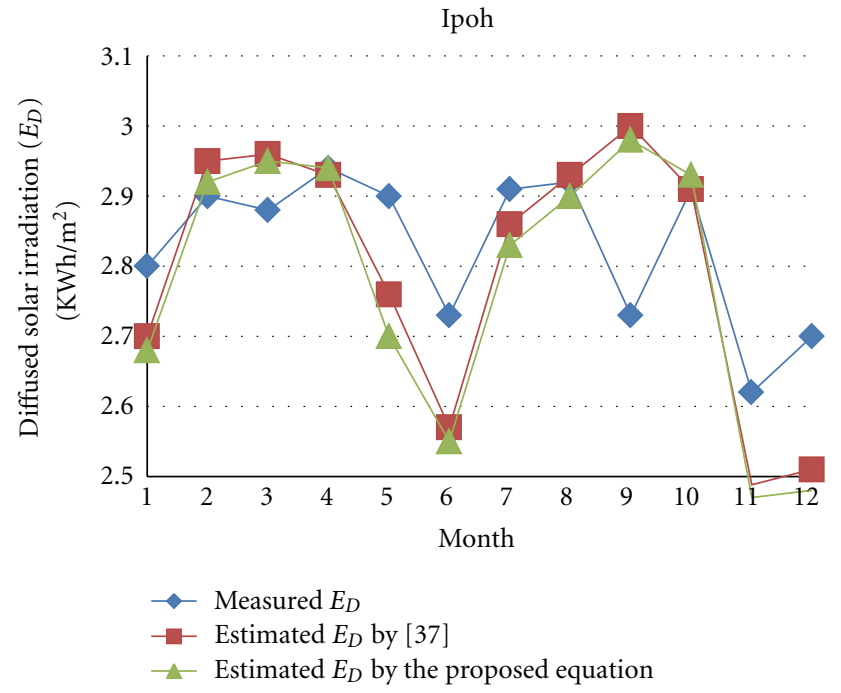

(d)

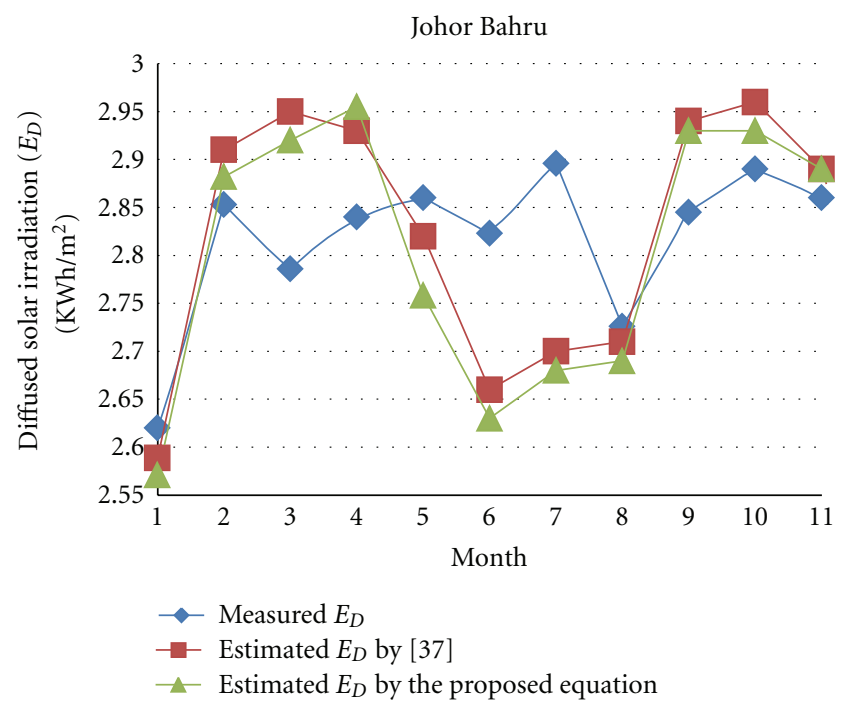

(e)

FIGURE 9: Comparison between the monthly average of the predicted and the measured diffused solar irradiations. 
average MAPE, MBE, and RMSE for the predicted global solar irradiation are 5.92\%, 1.46\%, and 7.96. The MAPE in estimating the diffused solar irradiation is $9.8 \%$.

\section{References}

[1] J. A. Duffie and W. A. Beckman, Solar Engineering of Thermal Processes, John Wiley and Sons, New York, NY, USA, 1991.

[2] S. Coppolino, "A new correlation between clearness index and relative sunshine," Renewable Energy, vol. 4, no. 4, pp. 417423, 1994.

[3] D. Elizondo, G. Hoogenboom, and R. W. McClendon, "Development of a neural network model to predict daily solar radiation," Agricultural and Forest Meteorology, vol. 71, no. 1-2, pp. 115-132, 1994.

[4] D. B. Williams and F. S. Zazueta, "Solar radiation estimation via neural network," in Proceedings of the 6th International Conference on Computers in Agriculture, pp. 140-146, ASAE, Cancun, Mexico, 1994.

[5] D. Williams and F. Zazueta, "Solar radiation estimation via neural network.," in Proceedings of the 6th International Conference on Radiation. Computers in Agriculture, pp. 1143-1149, Cancun, Mexico, 1996.

[6] M. Mohandes, S. Rehman, and T. O. Halawani, "Estimation of global solar radiation using artificial neural networks," Renewable Energy, vol. 14, no. 1-4, pp. 179-184, 1998.

[7] S. M. Al-Alawi and H. A. Al-Hinai, "An ANN-based approach for predicting global radiation in locations with no direct measurement instrumentation," Renewable Energy, vol. 14, no. 1-4, pp. 199-204, 1998.

[8] A. Guessoum, S. Boubkeur, and A. Maafi, "A global irradiation model using radial basis function neural network," in Proceedings of the World Renew Energy Congress (WREC'98), pp. 332336, Oxford, UK, 1998.

[9] L. Hontoria, J. Riesco, P. Zufiria, and J. Aguilera, "Improved generation of hourly solar radiation artificial series using neural networks," in Proceedings of the Engineering Applications of Neural Networks (EANN'99), Warsaw, Poland, 1999.

[10] P. Zufiria, A. Vázquez, J. Riesco, J. Aguilera, and L. Hontoria, "A neural network approach for generating solar radiation artificial series," in Proceedings of the International WorkConference on Artificial and Natural Neural Networks (IWANN '99), Alicante, Spain, June 1999.

[11] M. Mohandes, A. Balghonaim, M. Kassas, S. Rehman, and T. O. Halawani, "Use of radial basis functions for estimating monthly mean daily solar radiation," Solar Energy, vol. 68, no. 2, pp. 161-168, 2000.

[12] L. Hontoria, J. Riesco, P. Zufiria, and J. Aguilera, "Application of neural networks in the solar radiation field. Obtainment of Solar Radiation Maps," in Proceedings of the 16th European Photovoltaic for Chemical Engineers, vol. 3, pp. 385-408, Elsevier, Amsterdam, The Netherlands, 2000.

[13] A. Sfetsos and A. H. Coonick, "Univariate and multivariate forecasting of hourly solar radiation with artificial intelligence techniques," Solar Energy, vol. 68, no. 2, pp. 169-178, 2000.

[14] G. Mihalakakou, M. Santamouris, and D. N. Asimakopoulos, "The total solar radiation time series simulation in Athens, using neural networks," Theoretical and Applied Climatology, vol. 66, no. 3-4, pp. 185-197, 2000.

[15] S. A. Kalogirou, "Artificial neural networks in renewable energy systems applications: a review," Renewable and Sustainable Energy Reviews, vol. 5, no. 4, pp. 373-401, 2000.
[16] L. Hontoria, J. Aguilera, J. Riesco, and P. Zufiria, "Recurrent neural supervised models for generating solar radiation synthetic series," Journal of Intelligent and Robotic Systems, vol. 31, no. 1-3, pp. 201-221, 2001.

[17] L. Hontoria, J. Aguilera, and P. Zufiria, "Generation of hourly irradiation synthetic series using the neural network multilayer perceptron," Solar Energy, vol. 72, no. 5, pp. 441446, 2002.

[18] A. S. S. Dorvio, J. A. Jervase, and A. Al-Lawati, "Solar radiation estimation using artificial neural networks," Applied Energy, vol. 74, pp. 307-319, 2002.

[19] F. Tymvios, C. P. Jacovides, and S. C. Michaelides, "The total solar energy on a horizontal level with the use of artificial neural networks," in Proceedings of the 6th Hellenic Conference of Meteorology, Climatology and Atmospheric Physics, pp. 2628, Ioannina, Greece, September 2002.

[20] S. Kalogirou, S. C. Michaelides, and F. S. Tymvios, "Prediction of maximum solar radiation using artificial neural networks," in Proceedings of the 7th World Renewable Energy Congress (WREC'02), 2002.

[21] K. S. Reddy and M. Ranjan, "Solar resource estimation using artificial neural networks and comparison with other correlation models," Energy Conversion and Management, vol. 44, no. 15, pp. 2519-2530, 2003.

[22] A. Sozen, E. Arcaklığlu, M. Ozalp, and EG Kanit, "Use of artificial neural networks for mapping the solar potential in Turkey," Applied Energy, vol. 77, pp. 273-286, 2004.

[23] A. Sozen, E. Arcaklığlu, and M. Ozalp, "Estimation of solar potential in Turkey by artificial neural networks using meteorological and geographical data," Energy Convers Manage, vol. 45, no. 18-19, pp. 3033-3052, 2004.

[24] A. Mellit, M. Benghanem, A. Hadj-Arab, and A. Guessoum, "Modeling of global solar radiation data from sunshine duration and temperature using the Radial Basis Function networks," in Proceedings of the IASTED International Conference on Modelling, Identification and Control (MIC '04), Grindelwald, Switzerland, February 2004.

[25] L. Hontoria, J. Aguilera, and P. Zufiria, "An application of the multilayer perceptron: solar radiation maps in Spain," Solar Energy, vol. 79, no. 5, pp. 523-530, 2005.

[26] A. Sozen, E. Arcaklyógblub, M. Ozalpa, and N. C. Agclarc, "Forecasting based on neural network approach of solar potential in Turkey," Renew Energy, vol. 30, pp. 1075-1090, 2005.

[27] F. S. Tymvios, C. P. Jacovides, S. C. Michaelides, and C. Scouteli, "Comparative study of Angstroms and artificial neural networks methodologies in estimating global solar radiation," Solar Energy, vol. 78, no. 6, pp. 752-762, 2005.

[28] A. Mellit, M. Benghanem, and M. Bendekhis, "Artificial neural network model for prediction solar radiation data: application for sizing stand-alone photovoltaic power system," in Proceedings of the IEEE Power Engineering Society General Meeting, vol. 1, pp. 40-44, June 2005.

[29] G. López, F. J. Batlles, and J. Tovar-Pescador, "Selection of input parameters to model direct solar irradiance by using artificial neural networks," Energy, vol. 30, no. 9, pp. 16751684, 2005.

[30] L. F. Zarzalejo, L. Ramirez, and J. Polo, “Artificial intelligence techniques applied to hourly global irradiance estimation from satellite-derived cloud index," Energy, vol. 30, no. 9, pp. 1685-1697, 2005.

[31] S. Alam, S. C. Kaushik, and S. N. Garg, "Computation of beam solar radiation at normal incidence using artificial neural 
network," Renewable Energy, vol. 31, no. 10, pp. 1483-1491, 2006.

[32] H. K. Elminir, Y. A. Azzam, and F. I. Younes, "Prediction of hourly and daily diffuse fraction using neural network, as compared to linear regression models," Energy, vol. 32, no. 8, pp. 1513-1523, 2007.

[33] G. López and C. A. Gueymard, "Clear-sky solar luminous efficacy determination using artificial neural networks," Solar Energy, vol. 81, no. 7, pp. 929-939, 2007.

[34] J. Mubiru and E. J. K. B. Banda, "Estimation of monthly average daily global solar irradiation using artificial neural networks," Solar Energy, vol. 82, no. 2, pp. 181-187, 2008.

[35] D. G. S. Chuah and S. L. Lee, "Solar radiation in peninsular Malaysia-Statistical presentations," Energy Conversion and Management, vol. 22, no. 1, pp. 71-84, 1982.

[36] K. Sopian and M. Y. H. Othman, "Estimates of monthly average daily global solar radiation in Malaysia," Renewable Energy, vol. 2, no. 3, pp. 319-325, 1992.

[37] T. Muneer, Solar Radiation and Daylight Models, Elsevier, London, UK, 2004.

[38] M. Caudill and C. Butler, Understanding Neural Networks: Computer Explorations, vol. 1 of Basic Networks, The MIT Press, Cambridge, Mass, USA, 1993. 


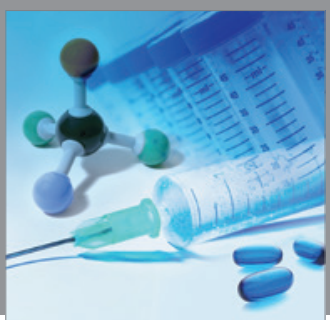

International Journal of

Medicinal Chemistry

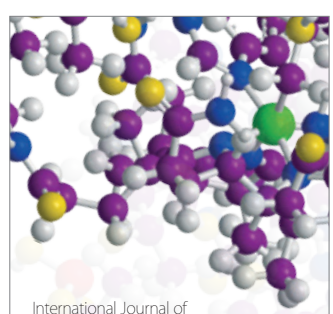

Carbohydrate Chemistry

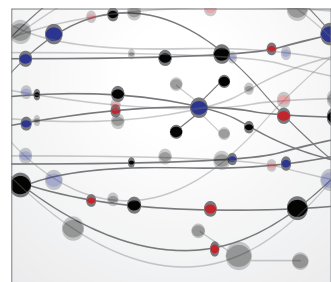

The Scientific World Journal
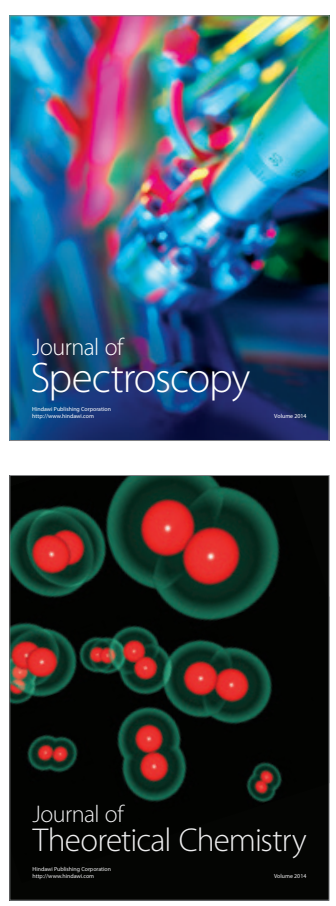
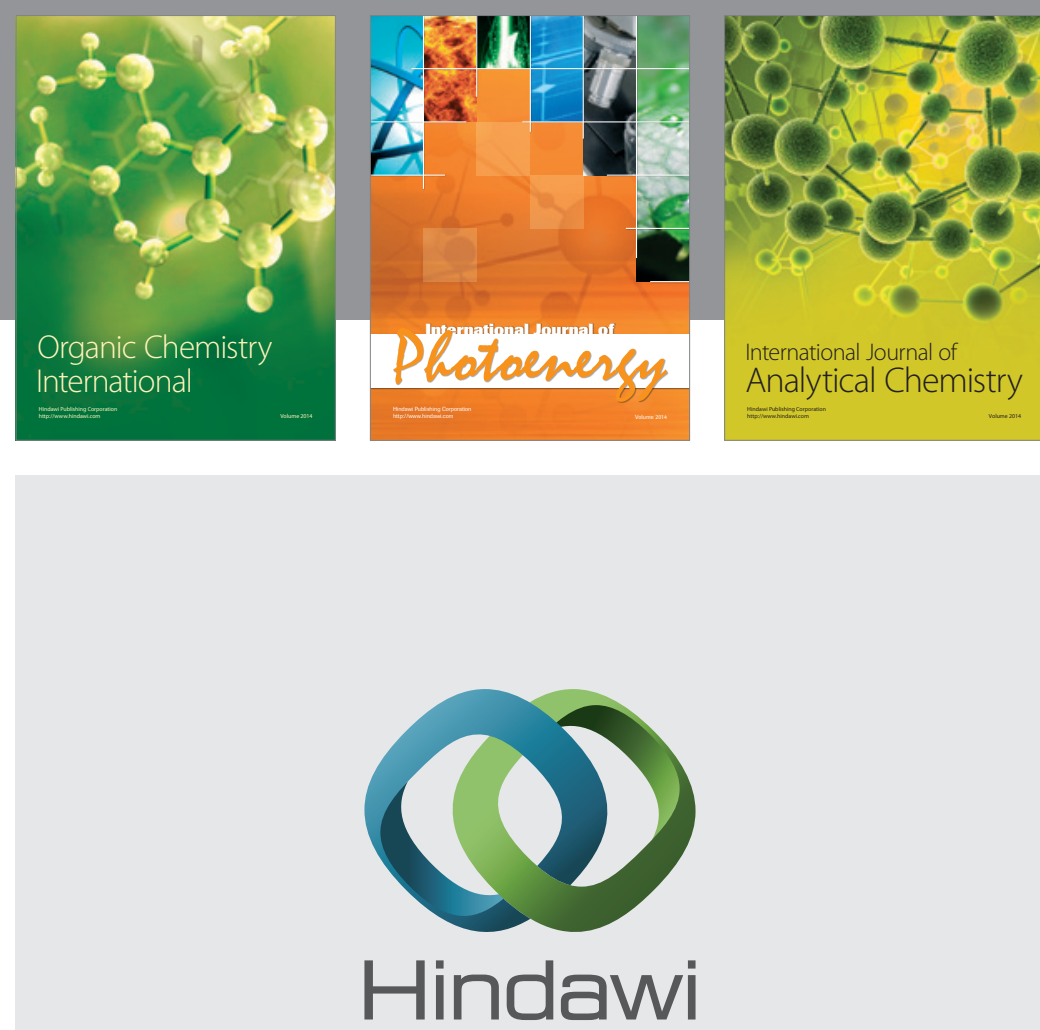

Submit your manuscripts at

http://www.hindawi.com
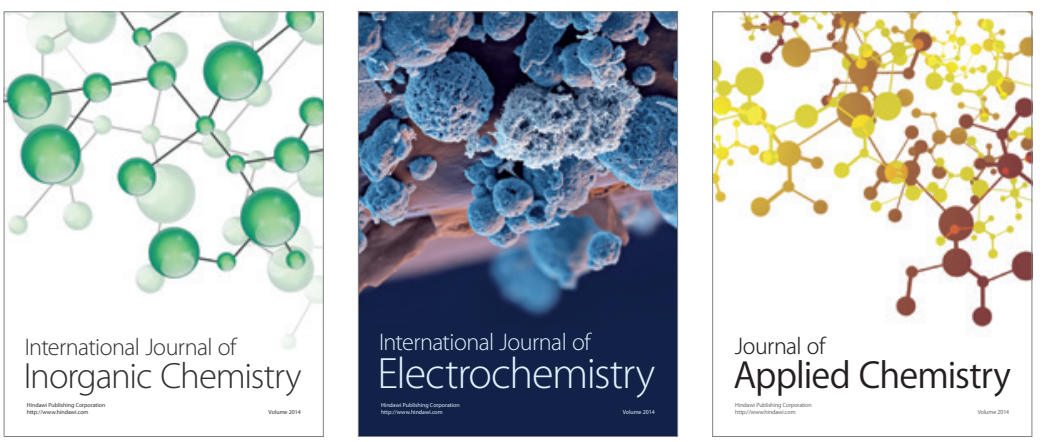

Journal of

Applied Chemistry
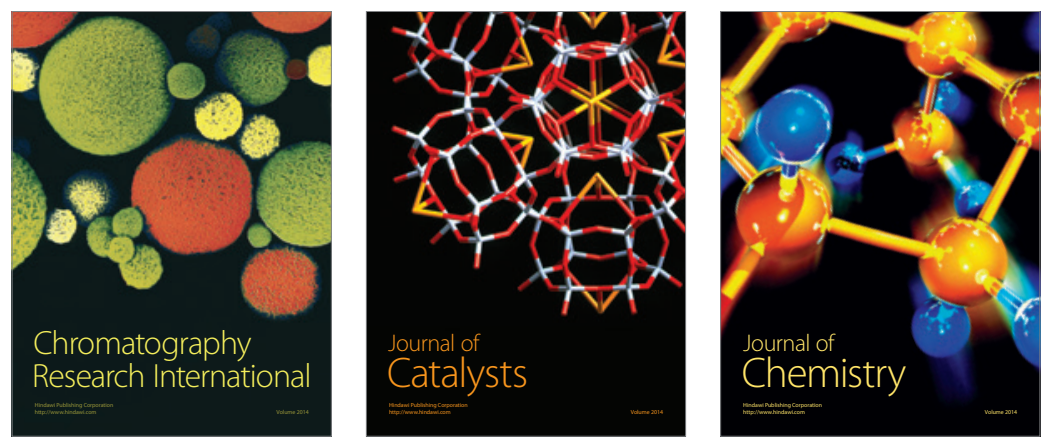
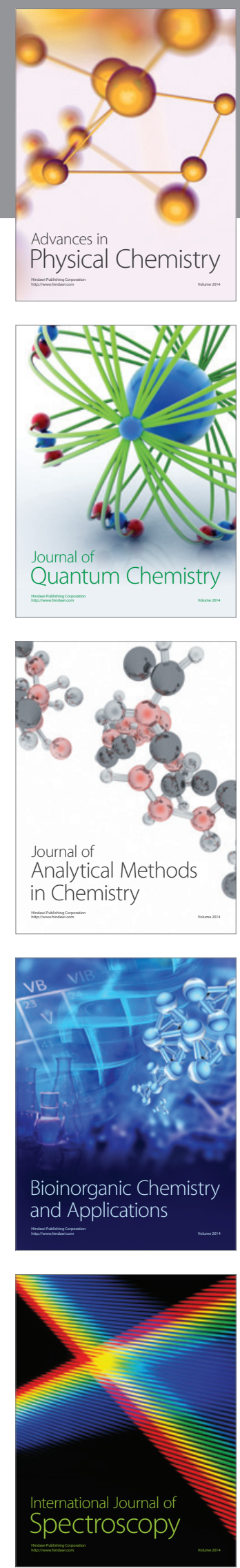